Check for updates

Cite this: Phys. Chem. Chem. Phys., 2018, 20, 20796

Received 23rd April 2018, Accepted 29th June 2018

DOI: $10.1039 / c 8 c p 02576 b$

rsc.li/pccp

\title{
Full elucidation of the transmembrane anion transport mechanism of squaramides using in silico investigations $\dagger$
}

\author{
Igor Marques, (D) a Pedro M. R. Costa, (D) a Margarida Q. Miranda, (D) a \\ Nathalie Busschaert, $\ddagger^{\mathrm{b}}$ Ethan N. W. Howe, ${ }^{\mathrm{bc}}$ Harriet J. Clarke, ${ }^{\mathrm{b}}$ \\ Cally J. E. Haynes, iD $\S^{\mathrm{b}}$ Isabelle L. Kirby, ${ }^{\mathrm{b}}$ Ananda M. Rodilla, ${ }^{\mathrm{d}}$ \\ Ricardo Pérez-Tomás, ${ }^{d}$ Philip A. Gale (iD *bc and Vítor Félix iD *a
}

\begin{abstract}
A comprehensive experimental and theoretical investigation of the transmembrane chloride transport promoted by four series of squaramide derivatives, with different degrees of fluorination, number of convergent $\mathrm{N}-\mathrm{H}$ binding units and conformational shapes, is reported. The experimental chloride binding and transport abilities of these small synthetic molecules in liposomes were rationalised with quantum descriptors and molecular dynamics simulations in POPC bilayers. The tripodal tren-based compounds, with three squaramide binding motifs, have high chloride affinity, isolating the anion from water molecules within the membrane model and preventing its release to the aqueous phase, in agreement with the absence of experimental transport activity. In contrast, the symmetrical monosquaramides, with moderate chloride binding affinity, are able to bind and release chloride either in the aqueous phase or at the membrane interface level, in line with experimentally observed high transport activity. The PMF profiles associated with the diffusion of these free transporters and their chloride complexes across phospholipid bilayers show that the assisted chloride translocation is thermodynamically favoured.
\end{abstract}

\section{Introduction}

The transport of biologically relevant ions across phospholipid bilayers is a vital process that relies on channel proteins. ${ }^{1,2}$ A range of disorders involving membrane channels occurs when they are non-existent, or their transport properties are perturbed, due to toxic, autoimmune, or genetic causes. ${ }^{1,2}$ For instance, the impairment of the cystic fibrosis transmembrane

\footnotetext{
${ }^{a}$ Department of Chemistry, CICECO - Aveiro Institute of Materials, University of Aveiro, 3810-193, Aveiro, Portugal.E-mail: vitor.felix@ua.pt

${ }^{b}$ Chemistry, University of Southampton, Southampton, SO17 1BJ, UK

${ }^{c}$ School of Chemistry, The University of Sydney, NSW 2006, Australia. E-mail: philip.gale@sydney.edu.au

${ }^{d}$ University of Barcelona, Faculty of Medicine, Dept. Pathology and Experimental Therapeutics, CCBRG, Barcelona, Spain

$\dagger$ Electronic supplementary information (ESI) available: Synthesis and characterisation, anion transport and anion binding assays, in vitro assays, detailed computational methods and extended discussion. CCDC 1590597 and 1460288 For ESI and crystallographic data in CIF or other electronic format see DOI: $10.1039 / \mathrm{c} 8 \mathrm{cp} 02576 \mathrm{~b}$

\$ Current address: Department of Chemistry, Tulane University, New Orleans, Louisiana 70118, USA.

$\S$ Current address: Department of Chemistry, University of Cambridge, Lensfield Road, Cambridge, CB2 1EW, UK.
}

conductance regulator (CFTR), an important epithelial transmembrane channel, affects both the transport of chloride and bicarbonate anions across epithelial cell membranes throughout the organism, resulting in male infertility and cystic fibrosis. ${ }^{2}$ Furthermore, chloride deficient transmembrane transport is also linked with other diseases, such as epilepsy, neurodegeneration, lung infections, renal salt loss, and kidney stones. ${ }^{3}$ A strategy for future therapeutic amelioration of the symptoms of this family of disorders is to replace the function of the faulty channels with small molecules. Thus, these so-called channel replacement therapies, that rely on anionophores to promote transmembrane anion transport, are currently being developed by the supramolecular chemistry community. ${ }^{4-20}$ Transporter molecules exploit different combinations of binding units and scaffolds (e.g., cholapods ${ }^{21,22}$ and tren-based molecules, ${ }^{23-26}$ using (thio)ureas; tambjamines; ${ }^{27-29}$ ortho-phenylene-diaminebased bis-ureas; $;^{30-32}$ calixpyrroles; ${ }^{33-36}$ anion- $\pi$ slides $;^{37-39}$ or, even more recently, molecules that rely on unconventional halogen ${ }^{40-43}$ and chalcogen bonds ${ }^{44}$ ) resulting in anion transporters that function either as mobile carriers or as artificial anion channels.

Squaramide derivatives are well characterised as ditopic receptors, both experimentally and computationally. ${ }^{45-57}$ Squaramide-based receptors, decorated with aromatic motifs, 


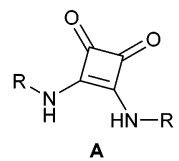

A

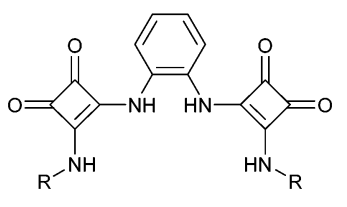

C

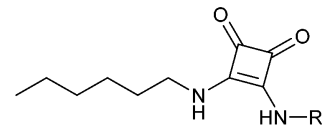

B

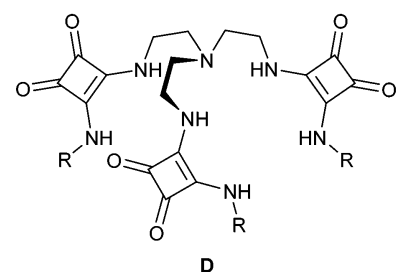

A1, B1, C1 and D1 $-\mathrm{R}=\mathrm{Ph}$

$A 2, B 2, C 2$ and $D 2-R=4-C F_{3} P h$

A3, B3, C3 and D3 $-\mathrm{R}=3,5-\left(\mathrm{CF}_{3}\right)_{2} \mathrm{Ph}$

Scheme 1 Squaramide-based receptors studied in this work.

are able to establish strong hydrogen bonding interactions with halides, showing a greater binding affinity then the analogous urea based receptors. ${ }^{55}$ Given their abilities as anion receptors, as well as their applicability in the field of medicinal chemistry, ${ }^{58-63}$ squaramide derivatives have been studied as anion transporters. ${ }^{64}$ Indeed, squaramides A1, A2 and A3 (see Scheme 1) were shown to be superior chloride transporters than the corresponding urea and thiourea analogues, as it was possible to improve their binding affinities without significantly changing their lipophilicities. ${ }^{64}$ The application of squaramide derivatives has also been expanded to the transport of amino-acids. ${ }^{65}$ On the other hand, the incorporation of the squaramide motifs into a steroidal framework has produced exceptional anion receptors, but poor anion transporters. ${ }^{66}$ Further tuning of the simple oxosquaramide derivatives A1-A3 involved their thionation to afford analogous thiosquaramides, which can enable/disable their transport ability as a function of the medium's $\mathrm{pH},{ }^{67}$ further increasing the range of potential applications of the squaramidebased transporters.

Molecular Dynamics (MD) simulations are a powerful tool to obtain energetic and structural insights into transmembrane transport, ${ }^{68}$ including drug delivery and ion traffic through protein channels. ${ }^{69,70}$ While in silico studies on these topics are quite common, MD studies on anion transport promoted by small synthetic molecules are still scarce. Our group has reported the diffusion of bis-indolylureas in a POPC bilayer, ${ }^{71}$ showing the importance of the interactions between these anionophores and the phospholipid head groups for effective transmembrane transport. Furthermore, a proof of concept study with a cationic calix[4]arene in a DOPC membrane allowed us to observe the passive transport of chloride assisted by a synthetic anion carrier for the first time. ${ }^{72}$ We have extended the MD investigations with membrane models to the study of the interaction of ortho-phenylene-diamine-based bisurea molecules ${ }^{30}$ and trenbased tris-thiourea compounds ${ }^{73}$ with POPC bilayers. More recently, MD studies on a series of dithioureidodecalin transporters with different alkyl chains lengths, allowed us to establish a relation between their transport abilities and their tilting and tumbling within the bilayer, which are slowed down by the increasing length of the alkyl chains via van der Waals interactions with phospholipid tails. ${ }^{74}$

Scheme 1 presents four series of structurally related squaramide derivatives, as follows: the A-series contains a single squaramide motif flanked by two aryl substituents, while in the B-series one of the aromatic groups is replaced by an $n$-hexyl substituent. The C-series' molecules are bis-squaramides based on an ortho-phenylene-diamine scaffold, while the D-series has three squaramide binding motifs appended to a tren scaffold. Overall, these series allow the systematic study of the effects of fluorination on the lipophilicity and anion binding strength, and how they can affect anion transport. Furthermore, the $\mathbf{C}$ and $\mathbf{D}$ families offer the possibility of investigating how different numbers of binding units, as well as their conformational dispositions, affect anion binding and transport. In this work, we report a comprehensive investigation on the twelve squaramide derivatives' transport properties, derived from a synergistic theoretical and experimental approach. This work has a clear focus on the structural and energetic features of these four series of molecules as anion carriers, while most of the experimental results are presented in the ESI. $\dagger$

\section{General methods}

\section{Receptor synthesis and characterisation, anion transport in liposomes and in vitro}

Synthesis and structural characterisation of B1, B3 and C1 are detailed in Section S2 of the ESI. $\dagger$ Moreover, the binding affinity of A1, A3, B1, B3, C1 and D1 towards physiologically relevant anions $\mathrm{Cl}^{-}, \mathrm{NO}_{3}{ }^{-}, \mathrm{HCO}_{3}{ }^{-}, \mathrm{H}_{2} \mathrm{PO}^{4-}$ and $\mathrm{SO}_{4}{ }^{2-}$ was elucidated by ${ }^{1} \mathrm{H}$ NMR titrations and are reported in Section S3 of the ESI. $\dagger$ Anion transport experiments in liposomes with B1, B3, C1 and D1 were performed as previously reported ${ }^{75}$ and are detailed in Section S4 of the ESI. $\dagger$ In vitro assays of A1, A3, B1, B3, C1 and D1 consisted of standard MTT assays, and staining with acridine orange and Hoechst 33342. Detailed procedures are given in Section S5 (ESI $\dagger$ ). Overall, equivalent experimental investigations were previously carried out for the remaining molecules shown in Scheme $1 .^{64,67,75-79}$

\section{Quantum calculations and MD simulations}

The atomistic characterisation of the squaramide derivatives as anion transmembrane transporters was assessed by DFT calculations followed by MD simulations in two membrane models, composed of 128 POPC lipids, ca. $0.15 \mathrm{M} \mathrm{NaCl}$ and different water : lipid ratios $(50.8: 1$ or $31.6: 1)$.

The DFT calculations, carried out with Gaussian $09,^{80}$ include the geometry optimisations of the free squaramide derivatives and their chloride complexes in gas phase, followed by the calculation of the $E^{2}$ energy values, and calculation of the distribution of electrostatic potential.

Overall, the anion transport properties of the squaramide derivatives were investigated with resort to MD simulations, using AMBER $14^{81}$ (passive diffusion), NAMD $2.9^{82}$ (Steered Molecular Dynamics) or AMBER $16^{83}$ (Umbrella Sampling simulations), 
with resort to GPU acceleration. ${ }^{84-86}$ The LIPID14 $4^{87}$ force field was employed for the POPC lipids, while $\mathrm{GAFF}^{88,89}$ parameters and atomic RESP charges $^{90}$ were used for the squaramide derivatives. The passive diffusion MD simulations mainly gave insights into the interactions between squaramide derivatives and POPC bilayer, while the US simulations allowed to reconstruct the energetic profile associated with the translocation of the A-series molecules along the bilayer normal. The detailed computational methods are given in Section S6.1 of the ESI. $\dagger$

\section{Results and discussion}

\section{Anion transport in liposomes}

We have previously reported the anion transport properties of the mono-squaramides $\mathbf{A 1}, \mathbf{A} \mathbf{2}$ and $\mathbf{A} 3,{ }^{64}$ as well as the more elaborate squaramides B2, C2, C3, D2, D3 ${ }^{75}$ and a series of cholapod-based squaramides. ${ }^{66}$ Much to our surprise, the bissquaramides (C2, C3 and the cholapods) only displayed modest chloride transport rates, while the tris-squaramides (D2 and D3) were completely inactive. This behaviour is in stark contrast with the high chloride transport ability of the mono-squaramides A1-A3,${ }^{64}$ and of analogous bis-ureas ${ }^{30,31}$ and tris-ureas. ${ }^{24,26}$ It was postulated that the exceptionally high anion binding strengths displayed by these squaramides has a detrimental effect on the anion transport rate. To fully understand this phenomenon, the series was extended to the structures shown in Scheme 1 (see ESI $\dagger$ for synthesis and characterisation).

Initially, standard $\mathrm{Cl}^{-} / \mathrm{NO}_{3}{ }^{-}$antiport assays were performed. Vesicles were loaded with a buffered $\mathrm{NaCl}$ solution $(489 \mathrm{mM}$, $\mathrm{pH}$ 7.2), dispersed in a buffered $\mathrm{NaNO}_{3}$ solution ( $489 \mathrm{mM}, \mathrm{pH}$ 7.2), and the chloride efflux induced by the various squaramides was monitored using a chloride selective electrode. The initial rates of chloride transport $\left(k_{\text {ini }}\right)$ obtained using this assay are shown in Fig. 1b, and confirmed our previous observations. The A-series are the best performing squaramides, while the tripodal D-series does not show any chloride transport activity. The same trend was also confirmed by concentration-dependent Hill analysis (Table S3, ESI $\dagger$ ), and for the transport of other anions such as $\mathrm{HCO}_{3}{ }^{-}$(Fig. S11, ESI $\dagger$ ). Chen et al. have recently assessed the anion transport ability of the tripodal D2 and D3 as well. ${ }^{91}$ In agreement with our results, they observed little anion transport activity in $\mathrm{Cl}^{-} / \mathrm{NO}_{3}{ }^{-}$antiport assays. However, these authors did report some anion transport activity for D2 and D3 in the presence of a pH gradient, which we did not see using our HPTS assays (Fig. S20-S23, ESI $\dagger$ ). Nevertheless, the obtained $\mathrm{EC}_{50}$ values $(0.75 \mathrm{~mol} \% \text { for } \mathbf{D} 3)^{91}$ are still significantly higher than those reported for the A-series ( $0.00074 \mathrm{~mol} \%$ for $\mathbf{A} 3$ using a similar $\mathrm{pH}$ gradient) ${ }^{92}$ Therefore, the pertinent question remains: why do the tripodal squaramides exhibit inferior transport ability when compared to the mono-squaramides?

To understand the behaviour and transport mechanism of the squaramides in more detail, we conducted a series of additional anion transport experiments. Cholesterol and calcein leakage (a)
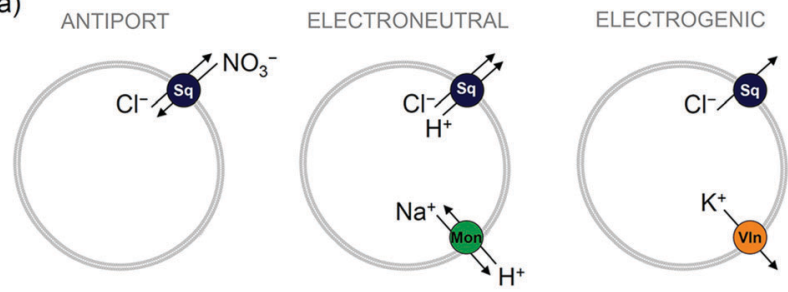

(b)

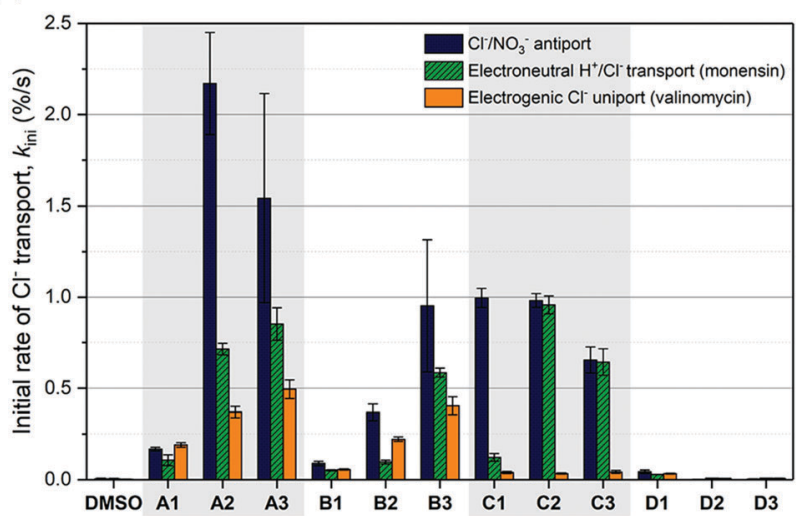

Fig. 1 Overview of the anion transport ability of the squaramides in liposomes. (a) Schematic lay-out of the experiments, where $\mathrm{Sq}=$ squaramide, Mon = monensin, and $V l n=$ valinomycin. (b) Initial rate of chloride transport calculated by asymptotic or linear fit for each squaramide (1 mol\%) under various assay conditions. Experimental conditions are as follows: ANTIPORT Unilamellar POPC vesicles were loaded with a $489 \mathrm{mM} \mathrm{NaCl}$ solution buffered to $\mathrm{pH} 7.2$ with $5 \mathrm{mM}$ phosphate, and were suspended in a $489 \mathrm{mM} \mathrm{NaNO} 3$ solution buffered to $\mathrm{pH} 7.2$ with $5 \mathrm{mM}$ phosphate salts. The experiment was started by the addition of a DMSO solution of the appropriate squaramide ( 1 mol\% w.r.t. lipid) and terminated by the addition of detergent at $300 \mathrm{~s}$. ELECTRONEUTRAL - Unilamellar POPC vesicles were loaded with $300 \mathrm{mM} \mathrm{KCl}$ buffered to $\mathrm{pH} 7.2$ with $5 \mathrm{mM}$ phosphate salts and were suspended in $300 \mathrm{mM}$ potassium gluconate buffered to pH 7.2 with $5 \mathrm{mM}$ phosphate salts. The experiment was started by the addition of monensin ( $0.1 \mathrm{~mol} \%$ w.r.t. lipid) and squaramide ( $1 \mathrm{~mol} \%$ w.r.t. lipid), and terminated by the addition of detergent at $300 \mathrm{~s}$. ELECTROGENIC Unilamellar POPC vesicles were loaded with $300 \mathrm{mM} \mathrm{KCl}$ buffered to $\mathrm{pH} 7.2$ with $5 \mathrm{mM}$ phosphate salts and were suspended in $300 \mathrm{mM}$ potassium gluconate buffered to $\mathrm{pH} 7.2$ with $5 \mathrm{mM}$ phosphate salts. The experiment was started by the addition of valinomycin ( $0.1 \mathrm{~mol} \%$ w.r.t. lipid) and squaramide ( 1 mol\% w.r.t. lipid), and terminated by the addition of detergent at $300 \mathrm{~s}$.

assays provided evidence to support the hypothesis that the squaramides function as anion carriers and not as ion channels (Fig. S25-S27, ESI $\dagger$ ). We therefore wished to elucidate whether the diffusion of the carrier across the membrane can occur as a pure uniport event (electrogenic transport of chloride ions), an ion pair symport event (electroneutral transport), or a combination of both. This was achieved using previously reported assays ${ }^{92}$ depicted in Fig. 1a. In brief, unilamellar vesicles containing buffered $\mathrm{NaCl}$ or $\mathrm{KCl}$ solutions were suspended in an external solution containing buffered potassium gluconate. Exchange of internal chloride ions with external gluconate anions is not possible, due to the large size and highly polar nature of the gluconate anion. Efflux of chloride ions can therefore only occur if (1) electroneutral $\mathrm{H}^{+} / \mathrm{Cl}^{-}$(or $\mathrm{Cl}^{-} / \mathrm{OH}^{-}$) transport by 
the squaramide is compensated by electroneutral $\mathrm{H}^{+} / \mathrm{Na}^{+}$transport by monensin, or (2) electrogenic $\mathrm{Cl}^{-}$transport by the squaramide is neutralised by electrogenic $\mathrm{K}^{+}$transport by valinomycin. The results of these assays are summarised in Fig. 1b. Not surprisingly, the A-series (and the B-series) is capable of both fast electrogenic and electroneutral transport, while the D-series is unable to transport ions under any conditions. More interesting are the results observed for the $\mathbf{C}$-series, which appear to be only capable of transporting chloride ions through electroneutral transport but not electrogenic transport. This suggests that these bis-squaramides promote transport via a pure ion pair symport event, or via ion exchange at the water/lipid interface; therefore, translocation of the free receptor is not required to complete the process. A possible explanation for this behaviour is that diffusion is hindered due to strong binding of the $\mathbf{C}$-series to phospholipid head groups, which is likely given the high affinity of the squaramides for phosphate in both the solid state (Fig. S9, ESI $\dagger$ ) and in solution (Fig. S37-S42, ESI $\dagger$ ). The same observation can also explain why the bis-squaramides (C-series) are poorer transporters than the mono-squaramides (A-series), and why the tris-squaramides (D-series) do not display any transport activity at all. The bisand tris-squaramides have higher anion affinities and are thus expected to bind to the phospholipid head groups more strongly, which competes with the chloride transport mediated by these squaramides. Alternatively, it is also possible that the strong chloride binding ability of the $\mathbf{C}$ - and $\mathbf{D}$-series hinders the release of chloride ions and thus impedes anion transport. Nevertheless, the unexpectedly low anion transport ability of the bis- and tris-squaramides appears to be due to their exceptionally high anion binding properties, (which hinders transport due to problematic chloride release or due to competition with lipid head group binding). To investigate this hypothesis in more detail, extensive DFT and MD calculations were performed (vide infra).

We decided to investigate whether the anion transport ability correlates with the in vitro anticancer activity of the compounds. MTT assays were performed on a variety of cancer cells (PC3, A375 and A549) to investigate the cytotoxicity of the compounds. These assays confirmed our previous observation that mono-squaramide $\mathbf{A} 2$ is both the best anion transporter and displays the most pronounced cytotoxic effect, ${ }^{75}$ while the D-series has minimal activity (see Fig. S49, ESI $\dagger$ ). In addition, vital fluorescence microscopy using acridine orange, as well as Hoechst 33342 staining and FACS analysis confirmed that the cytotoxicity of the squaramides is probably due to induction of apoptosis and/or changes in lysosomal pH (Fig. S50-S52, ESI $\dagger$ ). However, we encountered problems with the solubility of these squaramides during the in vitro assays (particularly the heavily fluorinated meta- $\mathrm{CF}_{3}$ compounds, and the $\mathbf{C}$-series) and it is thus possible that the observed cytotoxicity is an underestimate of the real value.

\section{DFT calculations}

Fig. 2 shows the structures of the chloride complexes of A2, B2, C2 and D2, optimised in the gas phase using the M06-2X
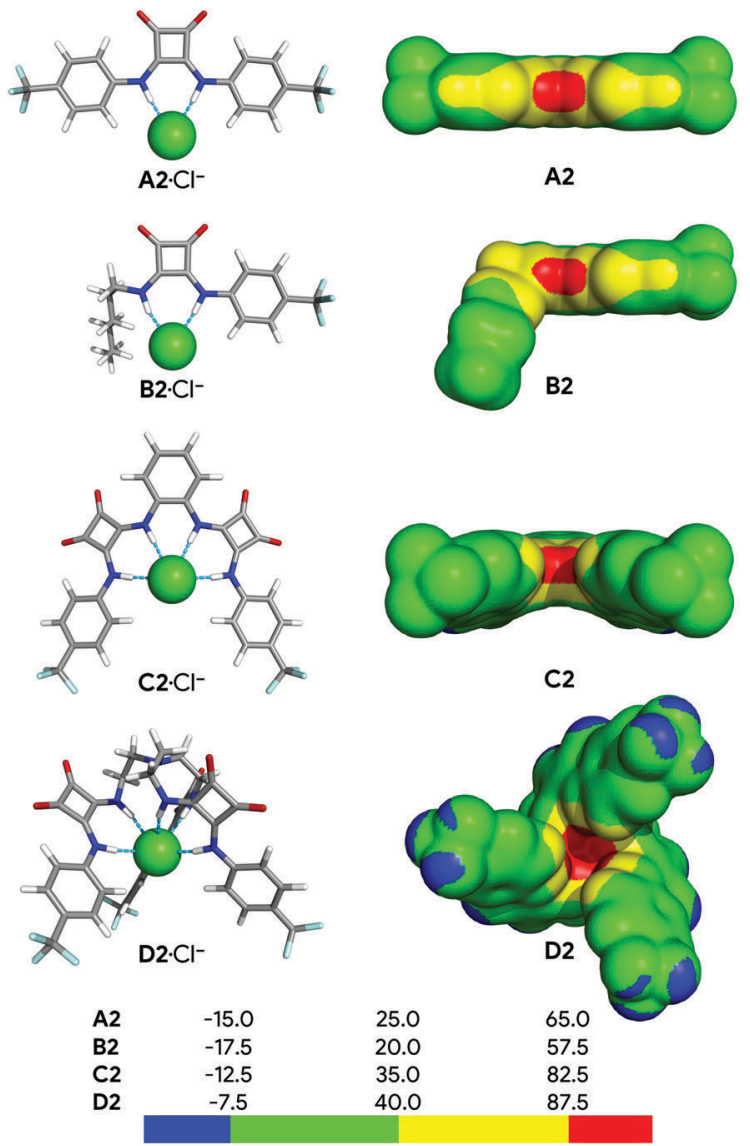

Fig. 2 Left: DFT optimised structures of the A2, B2, C2 and D2 chloride complexes. The hydrogen, carbon, oxygen, nitrogen, and fluorine atoms are shown in white, grey, red, blue and cyan sticks, respectively, while chloride is shown as a green sphere. Right: Distribution of the electrostatic potential mapped on the 0.001 electrons Bohr ${ }^{-3}$ isodensity surface of $\mathbf{A 2}$, B2, C2 and D2. The colour scales are given in $\mathrm{kcal} \mathrm{mol}^{-1}$.

functional and the $6-31+\mathrm{G}(\mathrm{d}, \mathrm{p})$ level of theory with Gaussian $09,^{80}$ while Fig. S53 (ESI $\dagger$ ) shows the remaining optimised complexes. The calculated $\mathrm{N} \cdots \mathrm{Cl}^{-}$distances and $\mathrm{N}-\mathrm{H} \cdots \mathrm{Cl}^{-}$angles are listed in Table S8 (ESI $\dagger$ ), as well as the values of the individual $\mathrm{N}_{\text {tren }}-\mathrm{C}-\mathrm{C}-\mathrm{N}$ torsion angles, starting at the tertiary nitrogen atom $\left(\mathrm{N}_{\text {tren }}\right)$ of the tripodal receptors $\mathbf{D}$.

Overall, the $\mathrm{N}-\mathrm{H} \cdots \mathrm{Cl}^{-}$hydrogen bonds are roughly linear, with the $\mathrm{N}-\mathrm{H} \cdots \mathrm{Cl}^{-}$angles ranging from $160.7^{\circ}$ to $177.7^{\circ}$, while the $\mathrm{N} \cdot \mathrm{Cl}^{-}$distances decrease along each individual series, indicating that these intermolecular interactions become stronger with the increasing fluorination degree (see Section S6.4 in the ESI $\dagger$ ). Subsequently, the effect of the different degrees of fluorination on the strength of the bonding interactions was evaluated using the distribution of the electrostatic potential mapped onto the electron density surface $\left(V_{\mathrm{S}}\right),{ }^{93}$ as well as the $E^{2}$ energy derived from the 2nd Order Perturbation Theory Analysis. $^{94}$

The $V_{\mathrm{S}}$ of the squaramide ligands in their chloride complexes (see ESI $\dagger$ ) was determined at the same level of theory and is shown in Fig. 2 for A2, B2, C2 and D2, and in Fig. S53 (ESI $\dagger$ ) for the remaining molecules. It is important to note that the $V_{\mathrm{S}}$ 
were estimated through single point calculations from the DFT optimised structures of the complexes after removal of the chloride ion. In these circumstances, as the spatial disposition of the $\mathrm{N}-\mathrm{H}$ binding units of the receptor is maintained, the electrostatic potential becomes more welldefined, leading to higher $V_{\mathrm{S} \text {, max }}$ values than would be expected. The linear squaramides of the $\mathbf{A}^{-}$and $\mathbf{B}$-series display a well-defined positive region (red) centred at the $\mathrm{N}-\mathrm{H}$ binding units while the most negative region (blue) covers the oxygen atoms of the carbonyl groups. In the molecules of the C-series the red region encompasses the four acidic $\mathrm{N}-\mathrm{H}$ binding units of the two squaramide motifs, while the carbonyl groups are surrounded by blue areas of negative potential. In the tripodal molecules, the most positive region is located inside the binding pocket enclosing all six $\mathrm{N}-\mathrm{H}$ binding units. On the other hand, in $\mathbf{D} 2$ and D3, the areas of negative potential, in addition to the carbonyl groups, also include the $-\mathrm{CF}_{3}$ moieties. The negative potentials (blue area) around the oxygen atoms of the carbonyl groups enable the squaramide motif to establish hydrogen bonds with putative hydrogen bond acceptors, such as the water molecules in a membrane system (vide infra) or other squaramide motifs, as observed in crystalline state. ${ }^{64,95}$ The maximum values of $V_{\mathrm{S}}\left(V_{\mathrm{S}, \max }\right)$, listed in Table 1 , mainly reflect the number and the position of the $-\mathrm{CF}_{3}$ electron withdrawing groups on the squaramide's phenyl substituents. Oddly enough, for $\mathbf{C 1}$ and $\mathbf{D} 1$ the $V_{\mathrm{S}, \max }$ values are comparable, despite the presence of an extra binding unit in the tripodal receptor. Moreover, the graphical representation of the transport rate $\left(k_{\text {ini }}\right)$ versus $V_{\mathrm{S} \text {,max }}$, depicted in Fig. 3 (red points), roughly follows a bell-shaped tendency (blue line), estimated by Bézier curve smoothing all data points (degree of 12). It is clear that the B-series, with low $V_{\mathrm{S}, \max }$ values, has moderate anion transport activity because of weak anion binding. The $\mathbf{C}$ - and $\mathbf{D}$-series, with low to no anion transport activity, have high and very high $V_{\mathrm{S} \text {,max }}$ values, binding anions too strongly and hampering their release. In stark contrast, $\mathbf{A} \mathbf{2}$ and $\mathbf{A} 3$, with intermediate $V_{\mathrm{S} \text {, max }}$ values are the most efficient transporters.

Table $1 E^{2}$ interaction energy values $\left(\mathrm{kcal}^{\mathrm{mol}}{ }^{-1}\right.$ ) for the $\mathrm{N}-\mathrm{H} \cdots \mathrm{Cl}^{-}$ hydrogen bonds in the gas phase DFT optimised structures of the chloride complexes, along with the $V_{\mathrm{s} \text {, max }}\left(\mathrm{kcal} \mathrm{mol}^{-1}\right)$ values for the squaramide ligands taken from the corresponding chloride complexes

\begin{tabular}{llr}
\hline Squaramide & $E^{2}$ & $V_{\mathrm{S}, \max }$ \\
\hline A1 & 65.60 & 77.27 \\
A2 & 72.74 & 88.32 \\
A3 & 81.23 & 94.78 \\
B1 & & \\
B2 & 60.06 & 72.62 \\
B3 & 60.92 & 78.22 \\
C1 & 68.38 & 81.58 \\
C2 & & \\
C3 & 79.25 & 99.66 \\
& 80.44 & 107.30 \\
D1 & 84.38 & 110.49 \\
D2 & & \\
D3 & 85.77 & 99.71 \\
& 85.92 & 110.46 \\
& 87.86 &
\end{tabular}

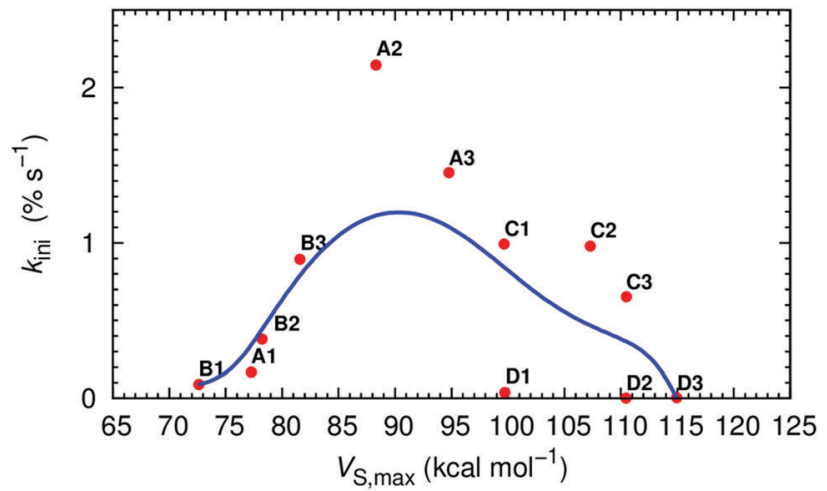

Fig. 3 Plot of $k_{\text {ini }}$ versus $V_{S \text {, max }}$ (red dots) and corresponding data smoothed Bézier curve (blue line).

The chloride binding strength in the squaramide complexes was further evaluated through the $E^{2}$ values, also listed in Table 1. The stabilisation energy of the squaramide complexes increases with the fluorination of the phenyl substituents, as a function of their electron withdrawing nature. Moreover, the $E^{2}$ values of the chloride complexes increase along with the $V_{\mathrm{S} \text {,max }}$ of the free receptors, being linear related $\left(R^{2}=0.90\right)$, and also yielding a similar profile when plotted against the anion transport data (see Fig. S54, ESI $\dagger$ ).

This comparison indicates that these quantum descriptors, intrinsically related with the binding ability of the squaramide derivatives for chloride, per se are insufficient for the accurate description of these small molecules as anion transporters. Thus, MD simulations were undertaken to gain further insights on the anion transport ability of these squaramide derivatives at the atomistic level, as follows.

\section{Passive diffusion MD simulations}

The MD simulations of the squaramide complexes on membrane systems were preceded by a force field parameterisation to more accurately reproduce the structure of the squaramide core in the phospholipid bilayer environment. This parameterisation was based in crystallographic data and is reported in the ESI $\dagger$ (see Section S6.7). The main purpose of the MD simulations is to assess the ability of the squaramide derivatives to interact with the POPC bilayer and to promote the chloride translocation.

The DFT optimised structures of the chloride complexes were either inserted into the water slab (scenario $\mathrm{W}$ ) or at the core (scenario M) of a POPC bilayer composed of 128 phospholipids. In addition, the anion carrier ability of these receptors was evaluated using distance restraints between the squaramide's binding sites and the chloride, leading to scenarios $\mathbf{W}^{\prime}$ and $\mathbf{M}^{\prime}$. Scenarios $\mathrm{W}$ and $\mathrm{W}^{\prime}$ allow the assessment of the passive diffusion of squaramide derivatives' complexes from the aqueous phase to the water/lipid interface, while the $\mathbf{M}$ and $\mathbf{M}^{\prime}$ scenarios enable the assessment of diffusion events that the chloride complexes experience within the highly-packed phospholipid bilayer. Furthermore, the $\mathrm{W}$ and $\mathrm{M}$ starting scenarios allow the monitoring, at the atomistic level, of the eventual chloride 
Table 2 Summary of the MD simulations carried out with squaramide chloride complexes in POPC membrane models for $200 \mathrm{~ns}^{\mathrm{a}}$

\begin{tabular}{|c|c|c|}
\hline \multirow[b]{3}{*}{ Squaramide } & \multicolumn{2}{|l|}{ Starting scenario } \\
\hline & $\mathrm{W} / \mathrm{W}^{\prime}$ & $\mathbf{M} / \mathbf{M}^{\prime}$ \\
\hline & Simulation IDs ${ }^{b}$ & Simulation IDs ${ }^{b}$ \\
\hline A1 & $\mathrm{W}_{1} \cdot \mathbf{A} 1, \mathrm{~W}_{2} \cdot \mathbf{A 1} / \mathrm{W}_{1}{ }^{\prime} \cdot \mathbf{A 1}$ & $\mathrm{M}_{1} \cdot \mathbf{A} 1, \mathrm{M}_{2} \cdot \mathbf{A} 1 / \mathrm{M}_{1}{ }^{\prime} \cdot \mathbf{A} 1$ \\
\hline $\mathbf{A 2}$ & $\mathrm{W}_{1} \cdot \mathbf{A} 2, \mathrm{~W}_{2} \cdot \mathbf{A} 2 / \mathrm{W}_{1}{ }^{\prime} \cdot \mathbf{A} 2$ & $\mathrm{M}_{1} \cdot \mathbf{A} 2, \mathrm{M}_{2} \cdot \mathbf{A} 2 / \mathrm{M}_{1}^{\prime} \cdot \mathbf{A} 2$ \\
\hline $\mathbf{A 3}$ & $\mathrm{W}_{1} \cdot \mathbf{A} \mathbf{3}, \mathrm{W}_{2} \cdot \mathbf{A} \mathbf{3} / \mathrm{W}_{1}{ }^{\prime} \cdot \mathbf{A} 3$ & $\mathrm{M}_{1} \cdot \mathbf{A} 3, \mathrm{M}_{2} \cdot \mathbf{A} 3 / \mathrm{M}_{1}{ }^{\prime} \cdot \mathbf{A} 3$ \\
\hline B1 & $\mathrm{W}_{1} \cdot \mathbf{B} 1, \mathrm{~W}_{2} \cdot \mathbf{B 1} / \mathrm{W}_{1}{ }^{\prime} \cdot \mathbf{B} 1$ & $\mathrm{M}_{1} \cdot \mathbf{B} 1, \mathrm{M}_{2} \cdot \mathbf{B} 1 / \mathrm{M}_{1}{ }^{\prime} \cdot \mathbf{B} 1$ \\
\hline $\mathbf{B} 2$ & $\mathrm{~W}_{1} \cdot \mathbf{B} 2, \mathrm{~W}_{2} \cdot \mathbf{B} 2 / \mathrm{W}_{1}{ }^{\prime} \cdot \mathbf{B} 2$ & $\mathrm{M}_{1} \cdot \mathbf{B} 2, \mathrm{M}_{2} \cdot \mathbf{B} 2 / \mathrm{M}_{1}^{\prime} \cdot \mathbf{B} 2$ \\
\hline B3 & $\mathrm{W}_{1} \cdot \mathrm{B} 3, \mathrm{~W}_{2} \cdot \mathrm{B} 3 / \mathrm{W}_{1}{ }^{\prime} \cdot \mathrm{B} 3$ & $\mathrm{M}_{1} \cdot \mathrm{B} 3, \mathrm{M}_{2} \cdot \mathrm{B} 3 / \mathrm{M}_{1}^{\prime} \cdot \mathbf{B} 3$ \\
\hline C1 & $\mathrm{W}_{1} \cdot \mathbf{C} \mathbf{1}, \mathrm{W}_{2} \cdot \mathbf{C} 1$ & $\mathrm{M}_{1} \cdot \mathrm{C} 1, \mathrm{M}_{2} \cdot \mathrm{C} 1$ \\
\hline C2 & $\mathrm{W}_{1} \cdot \mathbf{C} 2, \mathrm{~W}_{2} \cdot \mathrm{C} 2$ & $\mathrm{M}_{1} \cdot \mathrm{C} 2, \mathrm{M}_{2} \cdot \mathrm{C} 2$ \\
\hline $\mathbf{C} 3$ & $\mathrm{~W}_{1} \cdot \mathbf{C} 3, \mathrm{~W}_{2} \cdot \mathbf{C} 3$ & $\mathrm{M}_{1} \cdot \mathbf{C} 3, \mathrm{M}_{2} \cdot \mathbf{C} 3$ \\
\hline
\end{tabular}

D1 $\quad \mathrm{W}_{1} \cdot \mathbf{D 1}, \mathrm{W}_{2} \cdot \mathbf{D 1} \quad \mathrm{M}_{1} \cdot \mathbf{D} 1_{\mathrm{V}}, \mathrm{M}_{2} \cdot \mathbf{D} 1_{\mathrm{V}}, \mathrm{M}_{1} \cdot \mathbf{D} 1_{\mathrm{H}}, \mathbf{M}_{2} \cdot \mathbf{D} 1_{\mathrm{H}}{ }^{c}$ D2 $\quad \mathrm{W}_{1} \cdot \mathbf{D} 2, \mathrm{~W}_{2} \cdot \mathbf{D} 2 \quad \mathrm{M}_{1} \cdot \mathbf{D} 2_{\mathrm{V}}, \mathrm{M}_{2} \cdot \mathbf{D} 2_{\mathrm{V}}, \mathrm{M}_{1} \cdot \mathbf{D} 2_{\mathrm{H}}, \mathrm{M}_{2} \cdot \mathbf{D} 2_{\mathrm{H}}{ }^{c}$ D3 $\quad \mathrm{W}_{1} \cdot \mathbf{D} 3, \mathrm{~W}_{2} \cdot \mathbf{D} 3 \quad \mathrm{M}_{1} \cdot \mathbf{D} 3_{\mathrm{V}}, \mathrm{M}_{2} \cdot \mathbf{D} 3_{\mathrm{V}}, \mathrm{M}_{1} \cdot \mathbf{D} 3_{\mathrm{H}}, \mathrm{M}_{2} \cdot \mathbf{D} 3_{\mathrm{H}}{ }^{c}$

${ }^{a}$ Except for the MD simulation with the D-series in scenario M, which were 500 ns long. ${ }^{b}$ Each simulation ID results from the combination of the initial position of the transporter in the membrane system, the run number and the transporter. For instance, $\mathrm{W}_{1} \cdot \mathbf{A 1}$ stands for the first MD run carried out with A1 in setup W. ${ }^{c}$ The chloride complexes of D1, D2 and D3 were positioned within the membrane core either perpendicular to the bilayer normal (subscript $\mathrm{H}$ ) or parallel to it (subscript V).

release and uptake events, intrinsically associated with the anion carrier mechanism. These MD simulations also permit the evaluation of the preferential orientation of the transporters relatively to the bilayer normal, as well as the competitive hydrogen bonding interactions between the squaramide binding sites and the water molecules or phospholipids over the $\mathrm{N}-\mathrm{H} \cdots \mathrm{Cl}^{-}$bonding interactions. The simulated systems, as well as their MD simulation times, are summarised in Table 2 .

MD simulations with chloride complexes of linear squaramides $\mathbf{A}$ and $\mathbf{B}$. In agreement with the chloride efflux studies, ${ }^{75}$ MD simulations of the chloride complexes of the A- and B-series were carried out in scenario $\mathrm{W}$ for $200 \mathrm{~ns}$. The position of each squaramide derivative in the bilayer system was assessed throughout the production runs using the relative distance from the centre of mass defined by the two carbonyl groups $\left(\mathrm{C}=\mathrm{O}_{\mathrm{COM}}\right)$ to the closest membrane interface $\left(\mathrm{P}_{\mathrm{int}}\right.$, defined by the average position of the phosphorus atoms in that monolayer) measured along the $z$-dimension (the membrane normal, $\mathrm{C}=\mathrm{O}_{\mathrm{COM}} \cdots \mathrm{P}_{\text {int }}$ distance). Moreover, this distance, together with the relative distance between the centre of the mass of the nitrogen atoms from the two binding units and $\mathrm{P}_{\mathrm{int}}\left(\mathrm{N}-\mathrm{H}_{\mathrm{COM}} \cdots \mathrm{P}_{\text {int }}\right)$ gives the relative positioning of these carbonyl groups and $\mathrm{N}-\mathrm{H}$ binding sites towards the water/lipid interface.

The evolution of the $\mathrm{N}-\mathrm{H}_{\mathrm{COM}} \cdots \mathrm{P}_{\text {int }}$ and $\mathrm{C}=\mathrm{O}_{\mathrm{COM}} \cdots \mathrm{P}_{\text {int }}$ distances along the entire production run of simulation $\mathrm{W}_{1} \cdot \mathbf{A} 2$ is plotted in Fig. 4 (top), together with the number of hydrogen bonds that A2 establishes with any of the 19 chloride ions present in the system. The initially coordinated chloride and the $\mathrm{N}-\mathrm{H}$ binding sites are quickly solvated by the water molecules and the anion is released to the water phase, with disruption of the $\mathrm{N}-\mathrm{H} \cdots \mathrm{Cl}^{-}$hydrogen bonds (see Fig. 4 bottom, green dashed line).

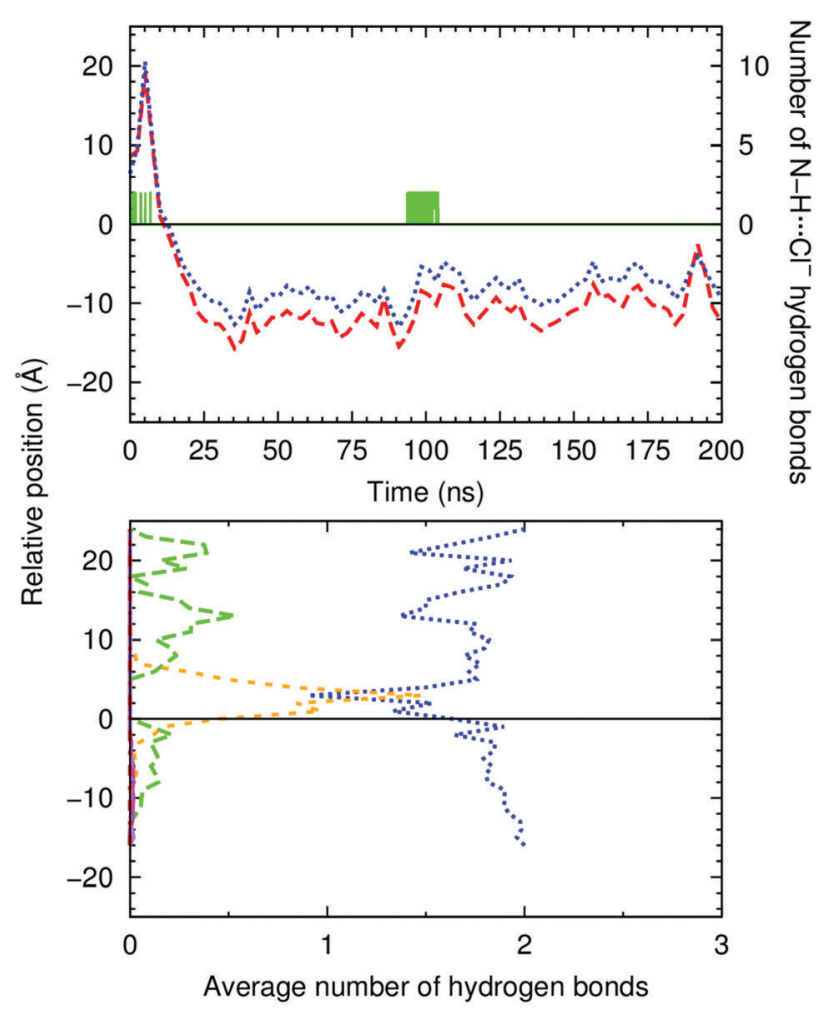

Fig. 4 A2's permeation of the water/lipid interface in MD simulation $\mathrm{W}_{1}$.A2. Top: Evolution of $\mathrm{C}=\mathrm{O}_{\mathrm{COM}} \cdots \mathrm{P}_{\text {int }}$ (red dashed line) and $\mathrm{N}-\mathrm{H}_{\mathrm{CO}} \cdots \mathrm{P}_{\text {int }}$ (blue dotted line) distances. The evolution of the number of $\mathrm{N}-\mathrm{H} \cdots \mathrm{Cl}^{-}$ hydrogen bonds is also plotted as a green solid line. The water/lipid interface is represented as a black line at $z=0 \AA$. Bottom: Average number of hydrogen bonds versus the relative position of the COM of A2. The following colour scheme was used for the interactions between $\mathbf{A} 2$ and chloride ions (green dashed line), water molecules (blue dotted line), POPC head groups (orange short dashed line), and ester groups (magenta solid line for the sn-1 chains and purple dot-dashed line for the sn-2 chains). The water/lipid interface is represented as a black line at $z=0 \AA$.

Concomitantly, these hydrogen bonding interactions are replaced by $\mathrm{N}-\mathrm{H} \cdots \mathrm{OH}_{2}$, as evident in Fig. 4 (bottom, blue dotted line), with the plot of the count of these hydrogen bonds versus the relative position of $\mathbf{A} 2$ along the bilayer normal ( $z$-dimension). Afterwards, as $\mathbf{A 2}$ approaches the interface, some of the $\mathrm{N}-\mathrm{H} \cdot \mathrm{OH}_{2}$ interactions are replaced by hydrogen bonds with the phosphate head groups $\left(\mathrm{N}-\mathrm{H} \cdots \mathrm{O}_{4} \mathrm{P}^{-}\right.$, orange short dashed line in Fig. 4, bottom). The diffusion of $\mathbf{A 2}$ from the water phase, illustrated in Fig. 5 with six selected snapshots taken from $\mathrm{MD}$ run $\mathrm{W}_{1} \cdot \mathbf{A} 2$, shows the squaramide derivative entering the phospholipid bilayer with a hydrophobic $-\mathrm{CF}_{3}$ group first. After 25 ns of simulation, the squaramide derivative is found completely embedded into the phospholipid bilayer. The evolution of the $\mathrm{N}-\mathrm{H}_{\mathrm{COM}} \cdots \mathrm{P}_{\text {int }}$ distance (blue line) shows that the binding units are closer to the water/lipid interface, while the $\mathrm{C}=\mathrm{O}_{\mathrm{COM}} \cdots \mathrm{P}_{\text {int }}$ relative distance (red line), systematically longer than the former one, indicates that the polar carbonyl groups point towards the lipophilic bilayer core - henceforth, this spatial disposition is type $\boldsymbol{a}$ (see Scheme 2). In addition, both $p-\mathrm{CF}_{3}-\mathrm{Ph}$ substituents adopt a roughly perpendicular disposition to the plane of the water/lipid interface, enabling the 


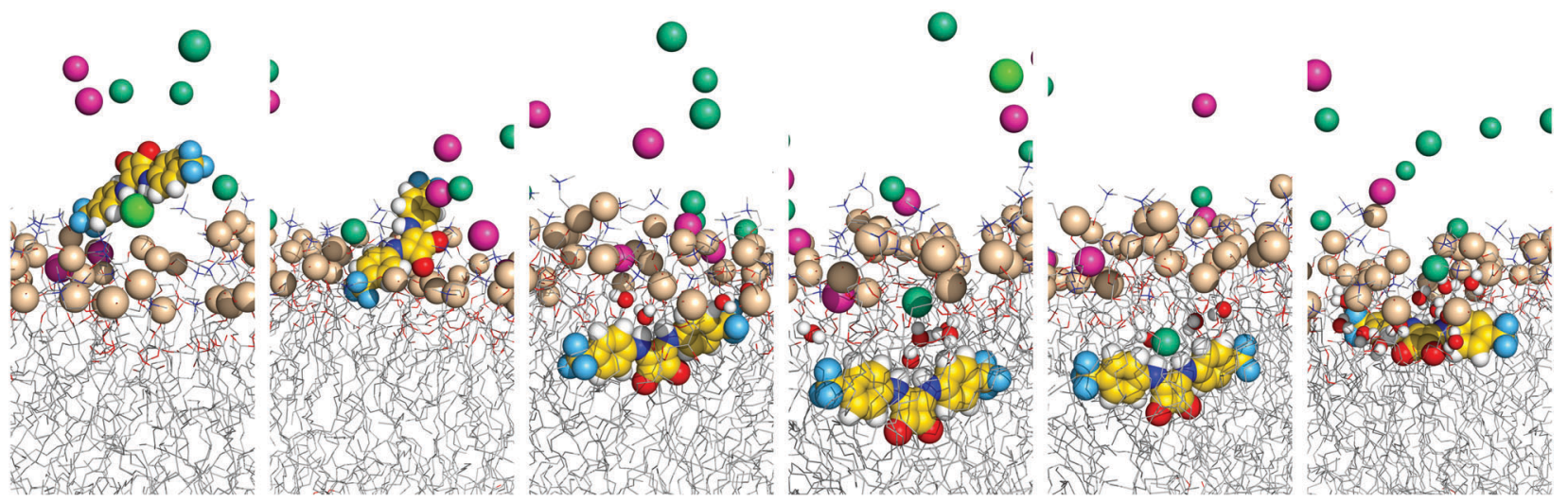

Fig. 5 Consecutive snapshots depicting the diffusion of the chloride complex of $\mathbf{A} 2$ throughout MD simulation $\mathbf{W}_{1} \cdot \mathbf{A} \mathbf{2}$. The squaramide derivative, sodium and chloride ions, together with the phosphorus atoms, are represented in spheres. The remaining atoms of the bilayer are shown as lines. The hydrogen atoms are shown in white, oxygen atoms in red, nitrogen atoms in blue, fluorine atoms in light blue, phosphorus atoms in wheat and carbon atoms in yellow (A2) or grey (phospholipids). The sodium ions are shown in pink and the chloride ions are shown in green (complex) or green marine (counter ions). The interaction of the internalised $\mathbf{A} \mathbf{2}$ with the solvent molecules is emphasised with the depiction of water molecules within $3.5 \AA$ from $\mathbf{A} 2$ as spheres. Most water molecules and the lipids' $\mathrm{C}-\mathrm{H}$ bonds are omitted for clarity.

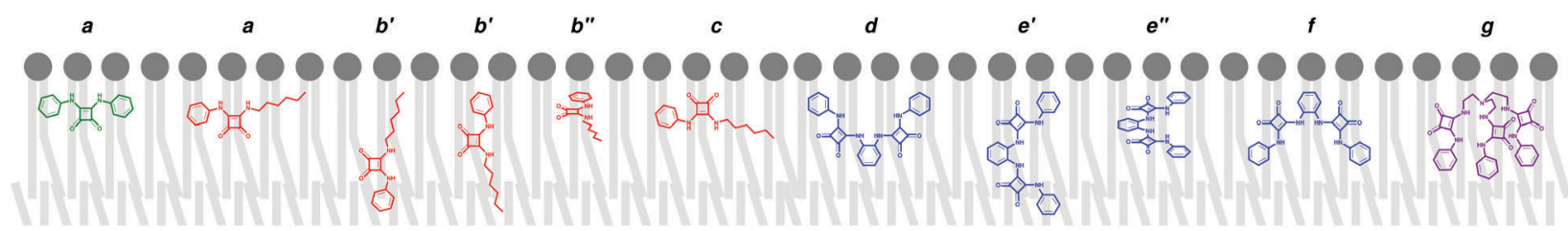

Scheme 2 Spatial dispositions adopted by the squaramide derivatives with respect to the lipid bilayer. Each series is represented by their nonfluorinated analogue (A1 - green; B1 - red; C1 - blue; D1 - purple).

rigid molecule $\mathbf{A} 2$ to establish $\mathrm{N}-\mathrm{H} \cdots \mathrm{O}$ hydrogen bonding interactions, mainly with water molecules, followed by interactions with carbonyl and the phospholipid head groups (see Fig. 4, bottom). Equivalent results can be found in Fig. S55 (ESI †) for the second run and for the MD simulations carried out with A1 and $\mathbf{A 3}$. In the MD simulations of $\mathbf{A 1}$ and $\mathbf{A 3}$, the squaramides' penetration is accompanied by a decrease of the $\mathrm{N}-\mathrm{H} \cdots \mathrm{OH}_{2}$ hydrogen bonds and concomitant increase of the $\mathrm{N}-\mathrm{H} \cdots \mathrm{O}_{4} \mathrm{P}^{-}$ interactions, at the interface level (see Fig. S56, ESI $\dagger$ ).

Overall, the evolution of the $\mathrm{N}-\mathrm{H} \cdots \mathrm{Cl}^{-}$(green line in Fig. 4 top and Fig. S55, ESI $\dagger$ ) shows that the A-series squaramides can recognise chloride throughout the passive diffusion in the bilayer system. Indeed, it is noteworthy that $\mathbf{A 2}$, in MD simulation $\mathrm{W}_{1} \cdot \mathbf{A 2}$, uptakes a solvated chloride ion for $10 \mathrm{~ns}$ (between the 93rd and 104th ns), while embedded in the membrane. This feature can be perceived by the increase of $\mathrm{N}-\mathrm{H} \cdots \mathrm{Cl}^{-}$bonding interactions in Fig. 4 (top), for the above-mentioned period, as well as in the last panels of Fig. 5 and in Movie S1 (ESI $\dagger$ ). However, in the second MD run of $\mathbf{A 2}$ in scenario $\mathrm{W}$, and in both MD runs of $\mathbf{A 1}$ and $\mathbf{A 3}$ (see Fig. S55, ESI $\dagger$ ), no chloride recognition events are observed after the internalisation of the small molecules. It is noteworthy that, in all these MD simulations, sporadic chloride recognition events in the water phase are monitored prior to the permeation of the water/lipid interface. The observed chloride uptake and release events are remarkable and show that these molecules have the potential to function as anion carriers. Moreover, the MD simulations suggest that the anion binding can either occur in the water phase or in the water/lipid interface (vide infra).

The B-series squaramides have an asymmetric structure, with the squaramide core decorated with an $n$-hexyl chain and a phenyl substituent accounting for different degrees of fluorination (vide Scheme 1) and lipophilicities. These two structural features dictate that additional dispositions to type $\boldsymbol{a}$ are adopted by this series of molecules in the phospholipid packed environment, as follows. In the MD simulations of the asymmetric squaramides $\mathbf{B}$, in addition to the $\mathrm{C}=\mathrm{O}_{\mathrm{COM}} \cdots \mathrm{P}_{\text {int }}$ and $\mathrm{N}-\mathrm{H}_{\mathrm{COM}} \cdots \mathrm{P}_{\text {int }}$ distances, the distance between the centre of mass of the aromatic ring $\left(\mathrm{Ph}_{\mathrm{COM}}\right)$ and the closest $\mathrm{P}_{\text {int }}\left(\mathrm{Ph}_{\mathrm{COM}} \cdots \mathrm{P}_{\text {int }}\right.$ distance), was evaluated to ascertain the relative orientation of $\mathbf{B 1}$, B2 or B3 towards the water/lipid interface. The evolution of these distances throughout the two independent MD runs is plotted in Fig. S57 (ESI $\dagger$ ). In the MD runs of the B-series in scenario W, after the water/lipid interface permeation, the squaramide core disposition of the free squaramide derivatives interchanges between type $\boldsymbol{a}$ and two other spatial dispositions, characterised by similar $\mathrm{C}=\mathrm{O}_{\mathrm{COM}} \cdots \mathrm{P}_{\text {int }}$ and $\mathrm{N}-\mathrm{H}_{\mathrm{COM}} \cdots \mathrm{P}_{\text {int }}$ distances (type $\boldsymbol{b}$ ) or a shorter $\mathrm{C}=\mathrm{O}_{\mathrm{COM}} \cdots \mathrm{P}_{\text {int }}$ distance than the $\mathrm{N}-\mathrm{H}_{\mathrm{COM}} \cdots \mathrm{P}_{\text {int }}$ distance (type $\boldsymbol{c}$ ).

Furthermore, the MD simulations have shown that the type $\boldsymbol{b}$ disposition must be subdivided in function of the $\mathrm{Ph}_{\mathrm{COM}} \cdots \mathrm{P}_{\text {int }}$ distance: in type $\boldsymbol{b}^{\prime}$ the squaramide core can be roughly perpendicular to the plane of the interface, while in type $\boldsymbol{b}^{\prime \prime}$ the squaramide core is almost parallel to the interface with 
three reference points approximately at the same distance to the interface. Furthermore, in type $\boldsymbol{b}^{\prime}$ the $\mathrm{Ph}_{\mathrm{COM}}$ is closer to or further from the closest membrane interface than the $\mathrm{C}=\mathrm{O}_{\mathrm{COM}}$ and $\mathrm{N}-\mathrm{H}_{\mathrm{COM}}$ reference points. The evolution of these distances is plotted in Fig. S57 (ESI $\dagger$ ) and the relevant spatial dispositions observed for the $\mathbf{B}$ molecules are also sketched in Scheme 2 and illustrated in Fig. S58 (ESI $\dagger$ ).

Overall, the analysis of the spatial dispositions can be related with the lipophilic character of the substituents present along these two series. Indeed, for the symmetric A-series, with equally lipophilic aromatic substituents, the main spatial disposition adopted is type $\boldsymbol{a}$. On the other hand, in the asymmetric B-series, the different lipophilic nature of the substituents leads to a frequent exchange between spatial dispositions with the prevalence of type $\boldsymbol{b}$ ones. With the increase of the lipophilic character of the aromatic substituents $(\log P$ values: $\mathrm{Ph}=2.05<$ $\left.4-\mathrm{CF}_{3} \mathrm{Ph}=2.93<3,5-\left(\mathrm{CF}_{3}\right)_{2} \mathrm{Ph}=3.81\right),{ }^{96}$ the $n$-hexyl substituent $(\log P=2.88)^{96}$ is closer to the water/lipid interface, rather than being aligned with the phospholipid tails. Throughout their diffusion along the membrane system, likewise the A-series, the squaramide core of the $\mathbf{B}$ molecules interacts with the POPC head groups and water molecules via hydrogen bonds, as can be seen in Fig. S56 (ESI $\dagger$ ).

Following the study of free $\mathbf{A}$ and $\mathbf{B}$ squaramides, the passive diffusion of their chloride complexes was also investigated for 200 ns using two $\mathrm{Cl}^{-} \ldots \mathrm{N}$ distances restraints (scenario $\mathrm{W}^{\prime}$ ). As shown in Fig. S59 (ESI $\dagger$ ), all complexes are able to permeate the water/lipid interface, staying below it until the end of simulation time, with the chloride widely exposed to a variable number of water molecules ranging between 0 and 9, as summarised in Table 3. On the other hand, the carbonyl moieties of the squaramide motifs, deeper in the POPC bilayer, have a negligible solvation.

The ability of these two mono-squaramide series to assist chloride transport by passive diffusion across the phospholipid bilayer was also investigated with the anion complexes inserted into the bilayer core with a random spatial disposition (scenario $\mathrm{M}$ ). The evolution of the $\mathrm{C}=\mathrm{O}_{\mathrm{COM}} \cdots \mathrm{P}_{\text {int }}$ and $\mathrm{N}-\mathrm{H}_{\mathrm{COM}} \cdots \mathrm{P}_{\text {int }}$ relative distances, plotted in Fig. S55 (ESI $\dagger$ ) for squaramides A, shows that during the first ps of MD production runs, the complexes of this series reorient within the packed phospholipid environment adopting mainly a type $\boldsymbol{a}$ disposition. Subsequently, the chloride ion is released before the complex reaches the water/ lipid interface, as indicated by the interruption of the $\mathrm{N}-\mathrm{H} \cdot \mathrm{Cl}^{-}$ interactions, also shown in Fig. S55 (green line) (ESI $\dagger$ ), accompanied by few water molecules. Afterwards, the free A squaramides nest between the phospholipids preserving the type $\boldsymbol{a}$ disposition, as in the MD simulations in scenario W. This sequence of diffusion events is illustrated in Fig. S60 (ESI $\dagger$ ) with selected snapshots obtained from simulation $\mathbf{M}_{1} \cdot \mathbf{A 3}$. It is also noteworthy that in this MD run, a chloride ion is taken up by embedded A3, near the end of the MD simulation for a period of ca. 20 ns (see Fig. S55, S60 and Movie S2, ESI $\dagger$ ). This is in line with the uptake event reported for simulation $\mathrm{W}_{1} \cdot \mathbf{A 2}$ (vide supra), emphasising the hypothesis that anion binding can occur at the water/lipid interface, rather than in the water phase.
Table 3 Average number of water molecules solvating the squaramide chloride complexes within the first solvation shell (cut-off $=3.4 \AA)^{a}$

\begin{tabular}{|c|c|c|c|}
\hline \multirow[b]{2}{*}{$\begin{array}{l}\text { MD } \\
\text { simulation }\end{array}$} & \multicolumn{3}{|c|}{ Solvated entity } \\
\hline & $\begin{array}{l}\text { Squaramide } \\
\text { derivative }\end{array}$ & $\begin{array}{l}\text { Carbonyl } \\
\text { groups }\end{array}$ & $\begin{array}{l}\text { Complexed } \\
\text { chloride }\end{array}$ \\
\hline $\mathrm{W}_{1}{ }^{\prime} \cdot \mathbf{A} 1^{c}$ & $9.2 \pm 3.6$ & $0.4 \pm 0.8$ & $3.7 \pm 1.0$ \\
\hline $\mathrm{W}_{1}{ }^{\prime} \cdot \mathbf{A} 2^{c}$ & $7.2 \pm 2.5$ & $0.2 \pm 0.5$ & $3.9 \pm 0.9$ \\
\hline $\mathrm{W}_{1}{ }^{\prime} \cdot \mathbf{A 3}^{c}$ & $9.7 \pm 10.4$ & $0.6 \pm 1.9$ & $3.7 \pm 1.1$ \\
\hline $\mathrm{W}_{1}{ }^{\prime} \cdot \mathbf{B} 1^{c}$ & $8.3 \pm 3.0$ & $0.5 \pm 0.8$ & $3.5 \pm 1.2$ \\
\hline $\mathrm{W}_{1}{ }^{\prime} \cdot \mathbf{B} 2^{c}$ & $8.1 \pm 3.1$ & $0.3 \pm 0.7$ & $4.1 \pm 1.1$ \\
\hline $\mathrm{W}_{1}^{\prime} \cdot \mathbf{B}^{c}$ & $10.1 \pm 3.6$ & $0.4 \pm 0.7$ & $3.8 \pm 0.9$ \\
\hline $\mathbf{M}_{1}{ }^{\prime} \cdot \mathbf{A 1}^{c}$ & $8.8 \pm 3.0$ & $0.4 \pm 0.8$ & $3.8 \pm 1.0$ \\
\hline $\mathbf{M}_{1}{ }^{\prime} \cdot \mathbf{A} 2^{c}$ & $6.6 \pm 2.6$ & $0.1 \pm 0.5$ & $3.5 \pm 1.3$ \\
\hline $\mathbf{M}_{1}{ }^{\prime} \cdot \mathbf{A 3}^{c}$ & $6.0 \pm 2.7$ & $0.0 \pm 0.3$ & $3.3 \pm 1.0$ \\
\hline $\mathbf{M}_{1}{ }^{\prime} \cdot \mathbf{B 1}^{c}$ & $10.0 \pm 3.2$ & $0.5 \pm 0.8$ & $4.2 \pm 1.0$ \\
\hline $\mathbf{M}_{1}{ }^{\prime} \cdot \mathbf{B 2}^{c}$ & $9.3 \pm 2.7$ & $0.6 \pm 0.8$ & $4.1 \pm 0.9$ \\
\hline $\mathbf{M}_{1}^{\prime} \cdot \mathbf{B 3}^{c}$ & $8.9 \pm 3.0$ & $0.4 \pm 0.6$ & $3.9 \pm 1.0$ \\
\hline $\mathbf{M} \cdot \mathbf{C} 1^{d}$ & $10.6 \pm 3.2$ & $1.5 \pm 1.5$ & $2.6 \pm 0.9$ \\
\hline $\mathbf{M} \cdot \mathbf{C} 2^{d}$ & $9.8 \pm 3.2$ & $2.2 \pm 1.8$ & $2.4 \pm 0.9$ \\
\hline $\mathbf{M} \cdot \mathbf{C} 3^{d}$ & $9.3 \pm 3.2$ & $2.1 \pm 1.7$ & $2.1 \pm 0.8$ \\
\hline $\mathbf{M} \cdot \mathbf{D} 1^{e}$ & $9.5 \pm 3.2$ & $4.5 \pm 2.3$ & $0.1 \pm 0.3$ \\
\hline $\mathbf{M} \cdot \mathbf{D} 2^{e}$ & $9.5 \pm 2.9$ & $4.2 \pm 2.1$ & $0.0 \pm 0.2$ \\
\hline $\mathbf{M} \cdot \mathbf{D} 3^{e}$ & $9.1 \pm 3.4$ & $4.2 \pm 2.3$ & $0.1 \pm 0.3$ \\
\hline
\end{tabular}

${ }^{a}$ These parameters were evaluated throughout the last $100 \mathrm{~ns}$ of simulation time for the A-, B- and C-series, and the last $400 \mathrm{~ns}$ for the D-series. ${ }^{b}$ Sum of the number of water molecules around the independent $\mathrm{C}=\mathrm{O}$ groups. ${ }^{c} N=10000 .{ }^{d}$ The data from the two individual runs were concatenated and treated together, resulting in $N=20000$. ${ }^{e}$ The data from the four individual runs (vertical and horizontal initial orientations) were concatenated and treated together, resulting in $N=160000$. The complete statistics for the individual MD runs can be found in Table S10 (ESI).

Likewise the A squaramide complexes, in the MD runs carried out with complexes of B-series squaramides in scenario $\mathbf{M}$, the chloride release towards the aqueous phase is promoted by water molecules. Furthermore, the spatial disposition adopted by the $\mathbf{B}$ molecules exchange between types $\boldsymbol{a}, \boldsymbol{b}$ and $\boldsymbol{c}$ (see Fig. S57, ESI $\dagger$ ), corroborating the insights reported for the MD simulations where their complexes are initially positioned in the water phase (scenario $\mathrm{W}$ ).

In the simulations carried out in the $\mathbf{M}^{\prime}$ scenario, the complexes promptly migrate to the water/lipid interface, as requested for the anion carrier mechanism. The complexes are disposed with the $\mathrm{N}-\mathrm{H}$ binding units close to the interface (see Fig. S59, ESI $\dagger$ ), the anion exposed to water molecules, and the $\mathrm{C}=\mathrm{O}$ pointing away from the aqueous phase (see Table 3 ).

MD simulations with chloride complexes of squaramides $\mathrm{C}$. The spatial dispositions of the $\mathbf{C}$ squaramide complexes during the passive diffusion along the membrane model were assessed using the following reference points: $\mathrm{N}-\mathrm{H}_{\mathrm{COM}}$ - centre of mass of the four nitrogen atoms of the binding units; $\mathrm{Sp}_{\mathrm{COM}}-$ the centre of mass of the aromatic ring in the 1,2-phenylenediamine spacer; and $\mathrm{Ph}_{\mathrm{COM}}$ - the centre of mass defined by the two aromatic substituents. With the evolution of the relative distances $\mathrm{N}-\mathrm{H}_{\mathrm{COM}} \cdots \mathrm{P}_{\text {int }}, \mathrm{Sp}_{\mathrm{COM}} \cdots \mathrm{P}_{\text {int }}$ and $\mathrm{Ph}_{\mathrm{COM}} \cdots \mathrm{P}_{\text {int }}$, (see Fig. S61, ESI $\dagger$ ), three main spatial dispositions (see Scheme 2) were discernible 
for the C-series: type $\boldsymbol{d}$, characterised by the aromatic substituents closer to the water phase and the 1,2-phenylenediamine spacer pointing to the bilayer core; type $\boldsymbol{e}^{\prime}$, with the overlap of the three reference points; type $\boldsymbol{e}^{\prime \prime}$, also characterised with the overlap of the three lines, but with the molecule adopting a perpendicular disposition towards the water/lipid interface; and type $\boldsymbol{f}$, with the aromatic substituents pointing to the bilayer core and the 1,2-phenylenediamine spacer near the water/lipid interface. All these spatial dispositions are depicted in Fig. S62 (ESI $\dagger$ ), with snapshots taken from both MD runs.

In both MD runs of non-fluorinated bis-squaramide $\mathbf{C 1}$, its spatial disposition interchanges between types $\boldsymbol{d}, \boldsymbol{e}^{\prime}, \boldsymbol{e}^{\prime \prime}$ and $\boldsymbol{f}$. In contrast, for the fluorinated $\mathbf{C 2}$ and $\mathbf{C 3}$, the evolution of the $\mathrm{N}-\mathrm{H}_{\mathrm{COM}} \cdots \mathrm{P}_{\text {int }}, \mathrm{Sp}_{\mathrm{COM}} \cdots \mathrm{P}_{\text {int }}$ and $\mathrm{Ph}_{\mathrm{COM}} \cdots \mathrm{P}_{\text {int }}$ distances indicates that these molecules adopt a type $\boldsymbol{f}$ spatial disposition with the hydrophobic substituents deeply embed into the bilayer. In addition, apart of MD simulation $\mathrm{W}_{1} \cdot \mathbf{C 2}$, the chloride complexes are maintained throughout most of the simulation time, as illustrated in Fig. S61 and S63 (ESI $\dagger$ ).

The diffusion of the chloride complexes of the $\mathbf{C}$-series within the phospholipid bilayer was also investigated (scenario $\mathbf{M}$ ), initially positioning the three anion complexes in the middle of the phospholipid molecules' tails. Moreover, due to the bulk of these molecules, the complexes were lodged almost parallel to the water/lipid interface plane (type $\boldsymbol{e}^{\prime}$ disposition). All complexes promptly diffuse towards the interface, as seen in Fig. S61 (ESI $\dagger$ ), and concomitantly reorient themselves, acquiring the same types of spatial dispositions as observed in MD simulations from the water phase (scenario $\mathrm{W}$, vide supra). While the main spatial dispositions of $\mathbf{C 2}$ and $\mathbf{C} 3$ anion complexes are unequivocally of type $\boldsymbol{f}$, non-fluorinated $\mathbf{C} \mathbf{1}$ adopted several spatial dispositions, as in scenario W. Overall, the complexes are highly hydrated when they reach the water/lipid interface (see Table 3), but the anion is firmly bound by the four cooperative $\mathrm{N}-\mathrm{H} \cdots \mathrm{Cl}^{-}$interactions, which preclude the anion release to the water phase (see Fig. S61, ESI $\dagger$ ). Thus, the MD simulations with the $\mathbf{C}$-series in scenarios $\mathrm{W}^{\prime}$ and $\mathbf{M}^{\prime}$ were not undertaken. Moreover, these structural insights obtained at the atomistic level are entirely consistent with the moderate transport ability experimentally observed for this series of molecules, suggesting that the low activity is more likely due to the problematic release of chloride, rather than competition with phospholipid head group binding.

MD simulations with chloride complexes of tripodal squaramides D. Throughout the MD simulations performed with the D-series in scenario $\mathrm{W}$, the position of the tripodal squaramidebased molecules was monitored using the relative distance between the central tripodal nitrogen $\left(\mathrm{N}_{\text {tren }}\right)$ and $\mathrm{P}_{\text {int }}\left(\mathrm{N}_{\text {tren }} \cdots \mathrm{P}_{\text {int }}\right.$ distance), measured along the membrane normal. The orientation of the $\mathbf{D}$-series squaramides was followed using this relative distance together with the $\mathrm{N}-\mathrm{H}_{\mathrm{COM}} \cdots \mathrm{P}_{\text {int }}$ and $\mathrm{Ph}_{\mathrm{COM}} \cdots \mathrm{P}_{\text {int }}$ distances, in which $\mathrm{Ph}_{\mathrm{COM}}$ is now the centre of mass defined by the aromatic carbon atoms from the three substituents and $\mathrm{N}-\mathrm{H}_{\mathrm{COM}}$ stands for the centre of mass defined by the nitrogen atoms of the six binding units.

The three tripodal molecules exhibit equivalent diffusion behaviours, being able to permeate the interface and residing below it in a well-defined spatial disposition until the end of the simulation time (vide infra). This spatial disposition of type $\boldsymbol{g}$ (see Scheme 2) is characterised by the $\mathrm{N}_{\text {tren }}$ and $\mathrm{N}-\mathrm{H}$ binding units near the interface level (orange and blue lines) and the aromatic substituents between the lipophilic tails (magenta line), as indicated by the evolution of the three relative distances for $W_{1}$.D3 plotted in Fig. 6, with the number of hydrogen bonds to chloride. The passive diffusion of this tripodal complex is also depicted in Fig. 7 with six snapshots taken from $\mathrm{W}_{1}$.D3. Equivalent plots for the remaining run of D3 and for the MD runs of D1 and D2 are shown in Fig. S64 (ESI $\dagger$ ).

Overall, the MD simulations of the D-series molecules are characterised by multiple chloride release and uptake events in the water phase, prior to the internalisation of the squaramide derivatives. However, due to the six convergent binding units, and higher value of $V_{\mathrm{S} \text {, max }}$, the initially complexed chloride is replaced by a hydrated chloride ion present in the system. Thus, in both MD runs of $\mathbf{D 1}$ in scenario W, the receptor enters the bilayer as chloride complex, which is preserved until the end of the MD simulation with up to six $\mathrm{N}-\mathrm{H} \cdots \mathrm{Cl}^{-}$hydrogen bonds (see Fig. S64 and S65, ESI $\dagger$ ). In contrast, in both MD runs of $\mathbf{D 2}$ and in simulation $\mathrm{W}_{2} \cdot \mathbf{D} 3$, the tripodal molecule loses its chloride before penetrating the bilayer. On the other hand, in the first MD run of D3, the initial anion complex is maintained for a long period of time, ca. $61 \mathrm{~ns}$, as the receptor lodges itself within the membrane, followed by the definitive anion release

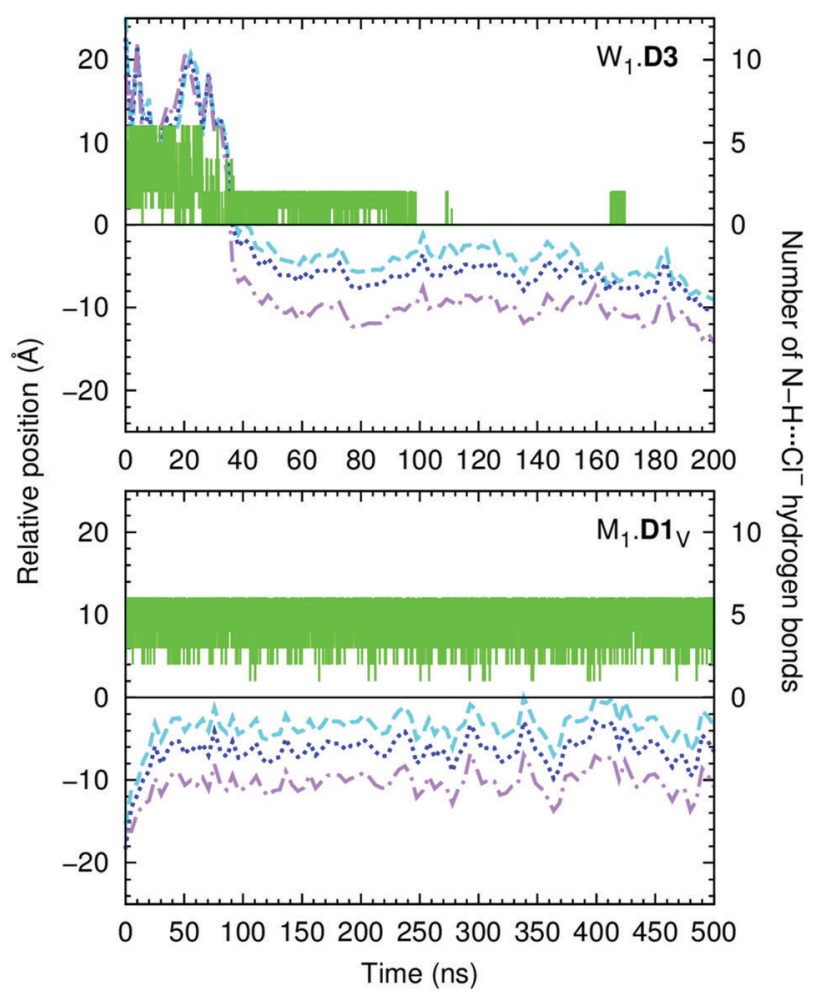

Fig. 6 Evolution of $\mathrm{N}_{\text {tren }} \cdots \mathrm{P}_{\text {int }}$ (cyan dashed line), $\mathrm{N}-\mathrm{H}_{\mathrm{CO}} \cdots \mathrm{P}_{\text {int }}$ (blue dotted line), and $\mathrm{Ph}_{\mathrm{CO}} \cdots \cdots \mathrm{P}_{\text {int }}$ (purple dot-dashed line) distances throughout MD simulations $W_{1} \cdot \mathbf{D} 3$ (top) and $M_{1} \cdot \mathbf{D} 1_{V}$ (bottom). The evolution of the number of $\mathrm{N}-\mathrm{H} \cdots \mathrm{Cl}^{-}$hydrogen bonds is also plotted as a green line. The water/lipid interface is represented as a black line at $z=0 \AA$. 

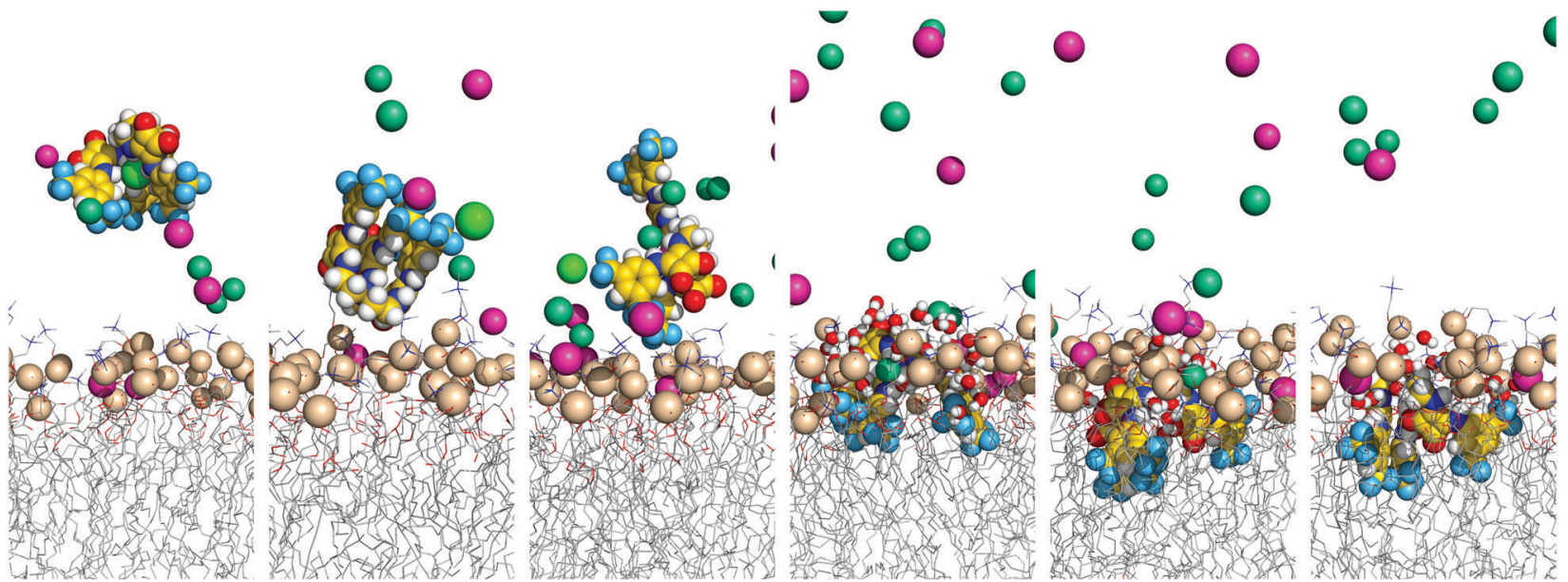

Fig. 7 Consecutive snapshots depicting the diffusion of the chloride complex of D3 throughout MD simulation $W_{1} \cdot$ D3. Remaining details as given in Fig. 5.

to the water phase. By the end of the MD sampling periods, all binding units of the internalised D2 and D3 are locked by hydrogen bonds established with lipid head groups, carbonyl groups of neighbouring squaramide moieties, or water molecules, as shown in Fig. S65 (ESI $\dagger$ ), where the number of hydrogen bonds is plotted versus the relative position of the receptor along the membrane normal. Indeed, apart of simulations $\mathrm{W}_{2} \cdot \mathbf{D} 2$ and $\mathrm{W}_{1}$. D3, the D-series molecules maintain the initial tripodal shape, characterised by three $\mathrm{N}_{\text {tren }}-\mathrm{C}-\mathrm{C}-\mathrm{N}$ torsion angles of ca. $\pm 60^{\circ}$, consistent with a ggg conformation, as thoroughly discussed in the ESI. $\dagger$

Like the $\mathbf{A}-$, B- and $\mathbf{C}$-series of squaramide molecules, the ability of the tripodal molecules to assist with chloride diffusion within the phospholipid bilayer was also ascertained in scenario M. Initially, the anion complexes were inserted into the POPC bilayer with the $C_{3}$ symmetry axis roughly parallel to the membrane normal. The variations on the $\mathrm{N}_{\text {tren }} \cdots \mathrm{P}_{\text {int }}$, $\mathrm{N}-\mathrm{H}_{\mathrm{COM}} \cdots \mathrm{P}_{\text {int }}$ and $\mathrm{Ph}_{\mathrm{COM}} \cdots \mathrm{P}_{\text {int }}$ distances along with the number of $\mathrm{N}-\mathrm{H}^{\cdots} \mathrm{Cl}^{-}$hydrogen bonds, for the long production runs of 500 ns are plotted in Fig. 6, for the MD run $\mathbf{M}_{1} \cdot \mathbf{D} 1_{\mathrm{V}}$, while the second run and the remaining MD simulations with D2 and D3 are represented in Fig. S67 (ESI $\dagger$ ). The histograms of the $\mathrm{N}_{\text {tren }}-\mathrm{C}-\mathrm{C}-\mathrm{N}$ torsion angles are plotted in Fig. S68 (ESI $\dagger$ ). Equivalent results were obtained for all runs, as discussed for the $\mathrm{M}_{1} \cdot \mathbf{D} 1$ run.

The complex D1 $\cdot \mathrm{Cl}^{-}$promptly diffuses towards the membrane interface with the phenyl groups pointing to the bilayer core, while the tripodal nitrogen atom and the carbonyl groups are closer to the water phase. This orientation is maintained until the end of the simulation time, with the ggg tripodal D1 receptor tightly bonded to chloride under the water/lipid interface. The pertinent diffusion events are illustrated in Fig. 8 (left) with three snapshots extracted from simulation $\mathbf{M}_{1} \cdot \mathbf{D} \mathbf{1}_{\mathrm{v}}$. The carbonyl groups of the D-series molecules are exposed to the water phase, being solvated by an average number of water molecules ranging between 3.7 and 4.9 (see Table 3). In contrast, the complexed chloride is rarely visited by water molecules throughout the last $400 \mathrm{~ns}$ of simulation time. In other words, the combination of the tripodal shape and the orientation of the complex shelters the chloride from the water molecules. The final orientation of D1 is entirely consistent with the negative electrostatic potential around the polar carbonyl groups (vide supra) and the
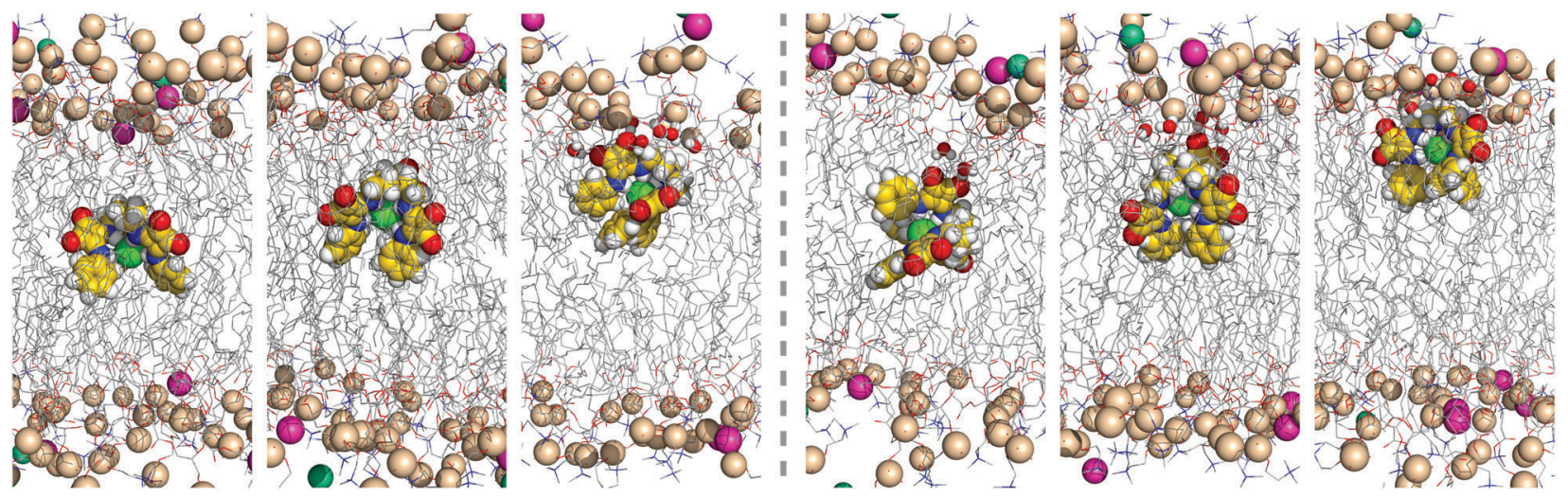

Fig. 8 Consecutive snapshots depicting the diffusion of the chloride complex of D1 throughout the first MD simulation run in scenario M: left - initial vertical orientation; right - initial horizontal orientation. Remaining details as given in Fig. 5. 
inherent lipophilic nature of the aromatic substituents of this tripodal molecule.

Having observed that the anion complexes of $\mathbf{D}$ have the ability to diffuse within the phospholipid bilayer, we decided to ascertain if the results reported above are dependent on the starting orientation of the tripodal anion complexes. Thus, the tripodal chloride complex was alternatively placed at the bilayer core with the $C_{3}$ symmetry axis perpendicular to the bilayer normal. The current discussion will focus on $\mathbf{M}_{1} \cdot \mathbf{D} \mathbf{1}_{\mathrm{H}}$, given that similar results were observed for the remaining $\mathrm{MD}$ run and simulated systems of D2 and D3. D1 $\mathrm{Cl}^{-}$promptly reorients itself during the first ns of the MD production run, concomitantly diffusing along the bilayer normal towards the water/lipid interface, as can be seen in Fig. S67 and S68 (ESI $\dagger$ ) and with selected snapshots of this MD simulation in Fig. 8 (right). In other words, equivalent diffusion events were observed independently of the initial orientation of the complex inside of the phospholipid bilayer, affording a type $\boldsymbol{g}$ orientation. The different passive diffusion events of the A- and D-series are shown in Movies S3 and S4 (ESI $\dagger$ ), respectively. As the D-series is able to permeate the water/lipid interface complexed to chloride and is unable to release it when placed in the membrane core, the MD simulations in scenarios $\mathrm{W}^{\prime}$ and $\mathbf{M}^{\prime}$ were not undertaken.

In summary, the tripodal chloride complexes are preserved during the extensive $6 \mu$ sampling period of scenario $\mathbf{M}$ simulations, which is entirely consistent with the inability of this series to operate the chloride transport, as experimentally observed. In other words, if these tripodal molecules are able to take up a chloride ion at the interface (as observed in some MD simulations of scenario $\mathrm{W}$ ), it is very unlikely that the chloride release to the water phase can occur, as required by an anion carrier mechanism. Furthermore, the MD insights suggest that the lack of transport activity is mainly due to the sheltering tripodal architecture synergistically associated with a superior binding affinity of the $\mathbf{D}$ molecules for chloride ion, which is characterised by higher $V_{\mathrm{S} \text {, max }}$ values inside of its tripodal conformation.

\section{Free energy calculations: steered molecular dynamics and umbrella sampling simulations}

The energetic barriers associated with the anion transmembrane transport for the A-series, the most active anion transporters, were estimated from the Potential of Mean Force (PMF) profiles obtained by combining US simulations and the Weighted Histogram Analysis Method (WHAM). ${ }^{97-99}$ The US simulations were preceded by SMD simulations to generate the starting positions of the three $\mathbf{A}$ free squaramides and their chloride complexes along the membrane normal (vide supra).

SMDs. Throughout the SMD simulations, several water molecules accompany the diffusing anion complexes or the free receptors, as plotted in Fig. S69 (ESI $\dagger$ ). The translocation of these entities across the bilayer drags many water molecules. However, the hydration of the squaramide derivatives decreases drastically as they are closer to the bilayer core $(z=0 \AA)$, from ca. 36 water molecules (for the smaller A1) to a minimum of ca. 3 at the centre of the POPC membrane. In the SMD simulations of the free transporters, these water molecules are hydrogen bonded to the $\mathrm{N}-\mathrm{H}$ binding sites, while in the chloride complexes they surround the anion.

PMFs. 67 US simulations were used to restore the PMF profile of each studied system. In each window, the orientation of the squaramide derivatives was monitored ascertaining the tilt angle $\alpha$ between the bilayer normal and the vector bisecting the $\mathrm{N}-\mathrm{H}$ binding sites and the carbonyl groups. An angle of $0^{\circ}$ or $180^{\circ}$ indicates that the vector and the bilayer normal are aligned; however, when the $\mathrm{N}-\mathrm{H}$ binding units are pointing in the negative direction of the membrane normal, $\alpha$ assumes a value of $0^{\circ}$, while an angle of $180^{\circ}$ indicates that the $\mathrm{N}-\mathrm{H}$ binding units of the squaramide motif point towards the positive direction of the $z$-dimension, as sketched in Fig. 9.

The $\alpha$ angle was histogrammed along the $z$-dimension for all systems and is plotted in Fig. 9 for US simulations of $\mathbf{A 1} \cdot \mathrm{Cl}^{-}$and in Fig. S70 (ESI $\dagger$ ) with the five remaining systems. Overall, in the water phase (for $z$-dimension values under $c a$. -20 and above $+20 \AA$ ), as expected, the squaramide derivatives adopt an undefined orientation in either free or complexed form. On the other hand, in the US windows comprised between -20 and $+20 \AA$, where the transporters are found within the POPC bilayer and restricted by the highly-packed lipid molecules, the $\alpha$ angles assume values close to $0^{\circ}$ or to $180^{\circ}$. In other words, during the US simulations' equilibration period, the molecules reoriented themselves, with the $\mathrm{N}-\mathrm{H}$ binding units always pointing to one of the water/lipid interfaces. This spatial orientation corresponds to a type $\boldsymbol{a}$ disposition previously observed in the passive diffusion MD simulations (vide supra), as illustrated in Fig. 10 with snapshots taken from different US windows and in Movie S5 (ESI $\dagger$ ). Consequently, these snapshots also enlighten the putative anion carrier mechanism proposed for these synthetic drug-like molecules.

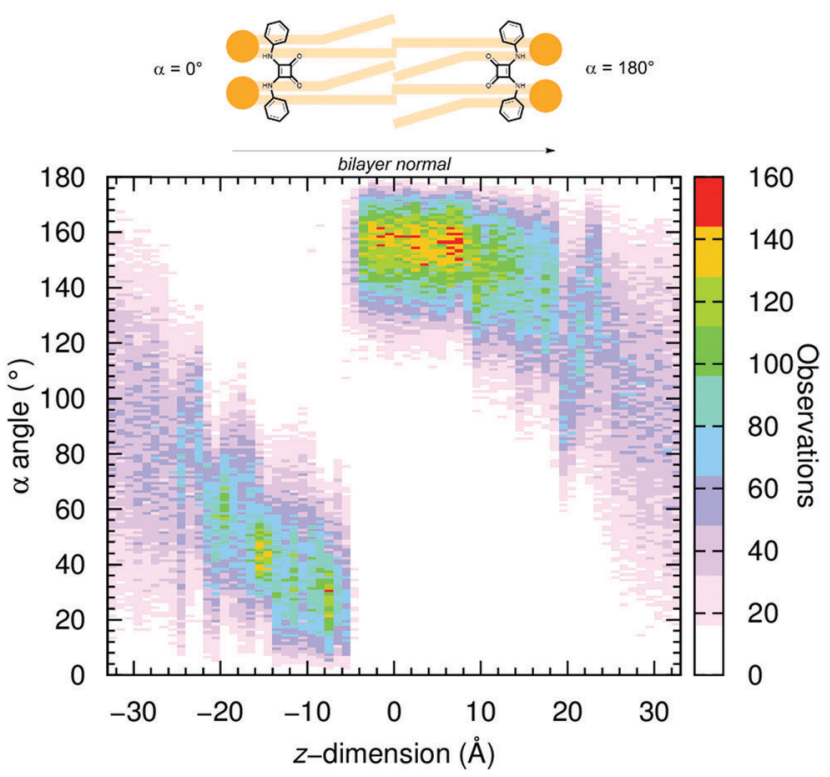

Fig. $92 \mathrm{D}$ histogram created from the $\alpha$ angle values monitored along the $z$-dimension position of the chloride complex of $\mathbf{A} \mathbf{1}$ throughout the 67 independent US windows. The colour ranges from white (no occurrence) to red (120 occurrences). 

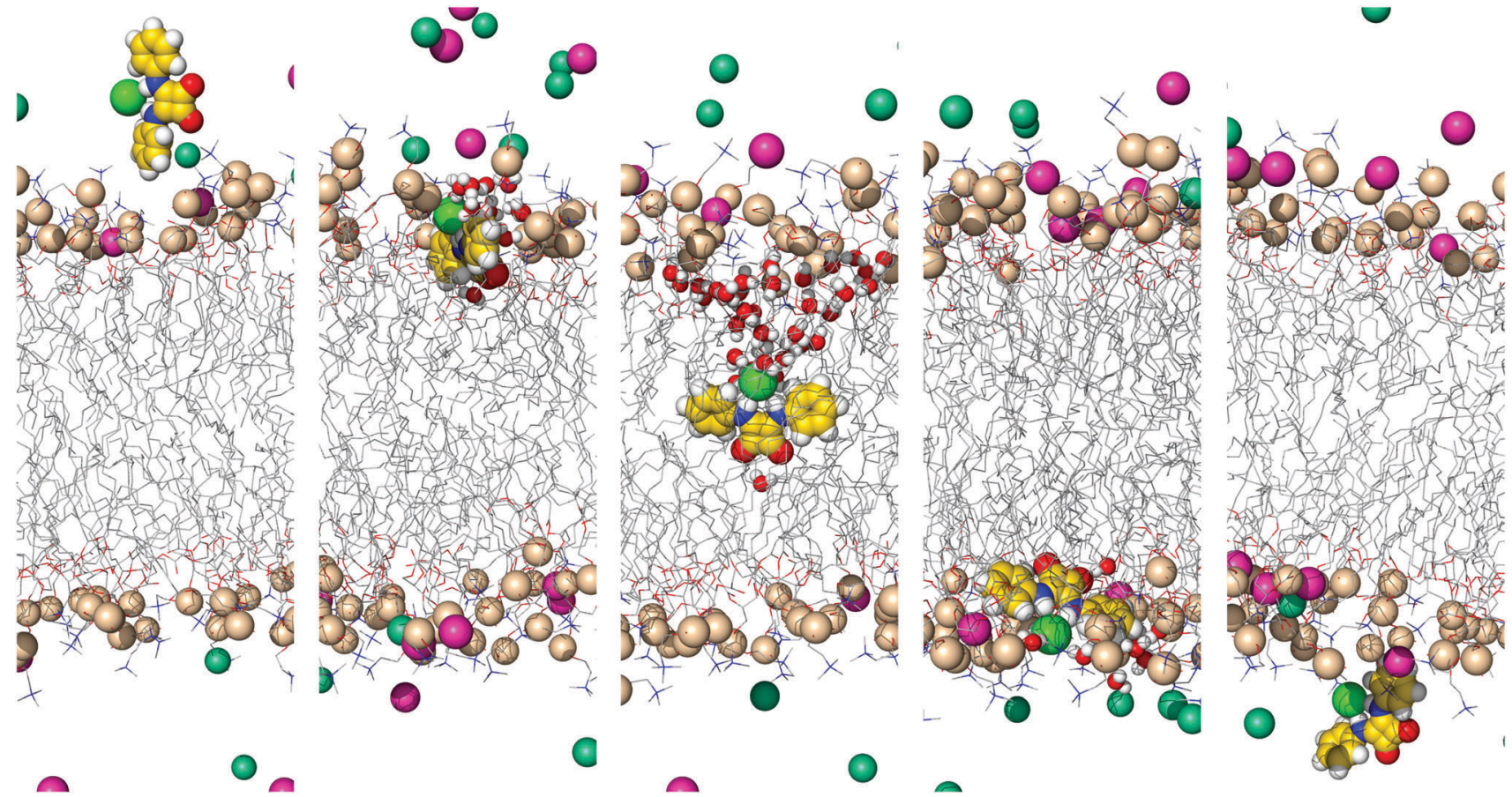

Fig. 10 Illustrative snapshots depicting the orientation of $\mathbf{A} 1 \cdot \mathrm{Cl}^{-}$in the US windows at $z=-30,-15,0,15$ and $30 \AA$ (from left to right). Remaining details as given in Fig. 5 .

The PMF profiles along the membrane normal were estimated for the three molecules of the $\mathbf{A}$-series, in their free and chloride complexed forms. For energetic comparison purposes, the PMF of a single free chloride was also estimated in the pure bilayer model used in this work. The energy profiles, normalised to zero in bulk water $(+33 \AA)$ and estimated spanning the whole membrane model are shown in Fig. 11, for the free transporters (top) and for their chloride complexes (bottom), together with the free chloride. The individual profiles with the corresponding errors, estimated with Monte Carlo Bootstrap analysis determined from 1000 random trials, ${ }^{100}$ are shown in Fig. S101-S103 (ESI $\dagger$ ). The PMF profiles, spanning the membrane, are asymmetric indicating that the entry and the exit of the POPC bilayer is accompanied by different interactions with water molecules and/or phospholipids, ${ }^{101}$ regardless of the orientation of the squaramide derivatives. The interactions of the small synthetic transporters with the water/lipid interface are discussed below. Each US sampling window was simulated for $50 \mathrm{~ns}$, with the last 20 ns being used to estimate the PMF profiles of the six systems, amounting to $1.34 \mu \mathrm{s}$ of sampling per system. The initial $30 \mathrm{~ns}$ were discarded as equilibration period, given that the PMF profiles only converged after this period as shown in Fig. S73 (ESI $\dagger$ ). On the other hand, for the free chloride, the US simulations were $25 \mathrm{~ns}$ long with the initial $15 \mathrm{~ns}$ corresponding to the equilibration period.

Overall, the profiles of the three complexes show that the three receptors lower the energetic barrier for the transmembrane transport of chloride, when compared with the free anion profile, thus being able to facilitate chloride transport as anion carriers. The presence of free $\mathbf{A} \mathbf{2}$ and $\mathbf{A} 3$ in bulk water after

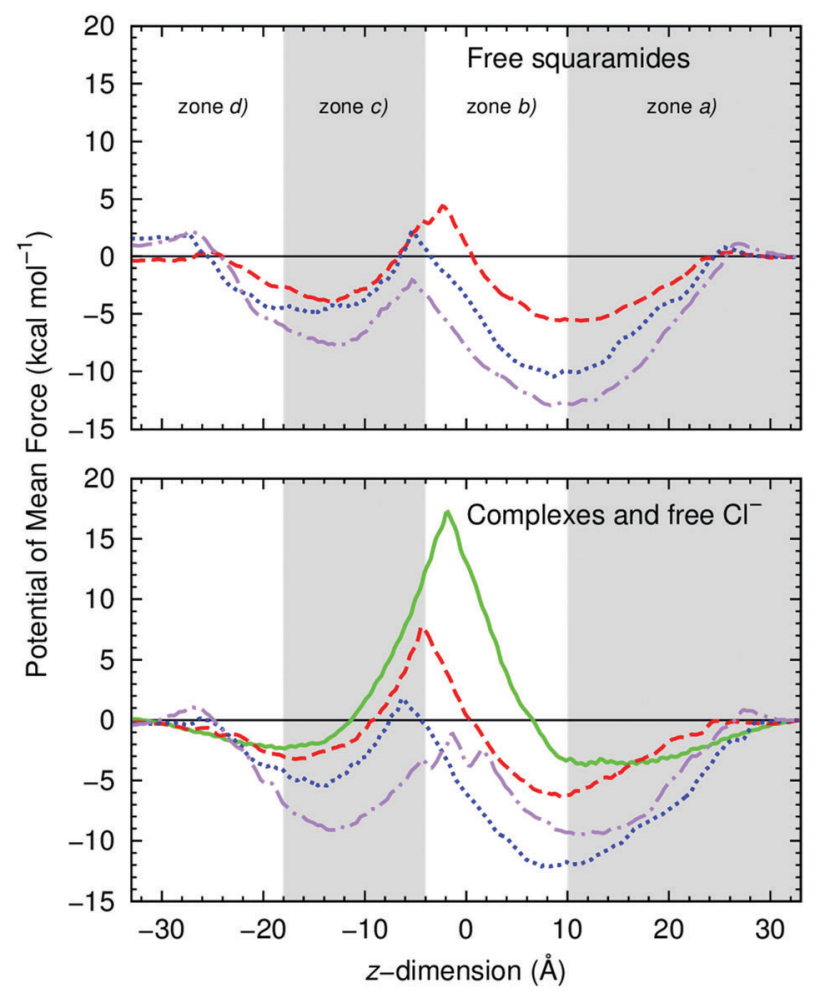

Fig. 11 PMF as a function of the $\mathbf{A}$ squaramides' distance to the membrane COM $(z=0 \AA)$, for the free squaramides (top) and for the chloride complexes (bottom). The red dashed lines, blue dotted lines and purple dot-dashed lines correspond to $\mathbf{A} \mathbf{1}, \mathbf{A} \mathbf{2}$ and $\mathbf{A} \mathbf{3}$, in this order, while the green solid line corresponds to the PMF of a free chloride. 
exiting the POPC bilayer $(z=-33 \AA)$ appears to be disfavoured by $c a .2 \mathrm{kcal} \mathrm{mol}^{-1}$ when compared to the opposite water phase $(z=+33 \AA)$. This small energy hysteresis is acceptable for these solvated molecules, given that in the PMF calculated for the membrane spanning of the smaller and neutral urea molecule, even with sampling times of $4.32 \mu \mathrm{s}$, an energy difference of ca. $1.5 \mathrm{kcal} \mathrm{mol}^{-1}$ was still present. ${ }^{102}$ The energy profiles are divided in four zones, identified in Fig. 11: (a) recognition and penetration of the bilayer, leading to the first basin; (b) the energetic barrier associated with diffusion within the highlypacked bilayer medium; (c) the second basin, after the core of the bilayer; and (d) before the protrusion of the opposite water/ lipid interface.

The diffusion of the A1 chloride complex is favoured by $6.4 \mathrm{kcal} \mathrm{mol}^{-1}$ at $z=9.4 \AA$, i.e., when the complex is nested just below the water/lipid interface and surrounded by few water molecules (zone a). The diffusion of the complex within the phospholipids' aliphatic tails (zone b), towards the bilayer core, naturally results in the increase of the energy barrier to a maximum of $c a .7 .7 \mathrm{kcal} \mathrm{mol}^{-1}$ at $z=-4.4 \AA$ A. The approach to the opposite water/lipid interface (zones c and d) is accompanied by the decrease of energy to $-3.2 \mathrm{kcal} \mathrm{mol}^{-1}$ at $z=-16.6 \AA$, as the complex is solvated with water molecules coming from the closest aqueous phase (see Fig. 10, with 5 snapshots). The energy profile of A2's chloride complex mirrors the PMF of $\mathbf{A 1} \cdot \mathrm{Cl}^{-}$, with the entry being lowered by $12.1 \mathrm{kcal} \mathrm{mol}^{-1}$, at $z=8.3 \AA$. The energy increases from -12.1 to $1.8 \mathrm{kcal} \mathrm{mol}^{-1}$ when the complex is positioned at $z=-6.1 \AA$. In contrast, the PMF of A3's chloride complex displays an energetic profile with two deep basins (zones a and c), at similar distances from the bilayer core ( $c a .13 \AA$ ) , with energy minima of $c a .-9.3 \mathrm{kcal} \mathrm{mol}^{-1}$ relative to the water phase. Between these basins, the maximum of $-1.1 \mathrm{kcal} \mathrm{mol}^{-1}$ occurs at $z=-1.4 \AA$ (zone b). This odd energy profile should be intimately linked with the higher lipophilic character of $\mathbf{A} \mathbf{3}$ when compared with the other two analogous. This complex "feels better" within the phospholipid environment and needs to overcome an energetic barrier of $c a .10 \mathrm{kcal} \mathrm{mol}^{-1}$ to leave the bilayer from $z=-13.2 \AA$ (zone d). At a similar position, the less lipophilic complexes need only to overcome barriers of $3.2\left(\mathbf{A 1} \cdot \mathrm{Cl}^{-}\right)$or $5.4\left(\mathbf{A 2} \cdot \mathrm{Cl}^{-}\right) \mathrm{kcal} \mathrm{mol}^{-1}$ barrier. In other words, while $\mathbf{A 1} \cdot \mathrm{Cl}^{-}$and $\mathbf{A 2} \cdot \mathrm{Cl}^{-}$have low energetic barriers to exit the bilayer, $\mathbf{A 3} \cdot \mathrm{Cl}^{-}$has to surmount a larger energy barrier to reach the water phase. In addition, $\mathbf{A 2} \cdot \mathrm{Cl}^{-}$has a smaller energetic barrier to cross the bilayer core, most likely due to its lipophilic character. These results indicate that $\mathbf{A} \mathbf{2}$ should be energetically favoured to assist the chloride transport when compared with the analogous $\mathbf{A 1}$ and $\mathbf{A 3}$, which is in line with the experimental transport studies.

The energy profiles associated with the diffusion of the free squaramide derivatives across the POPC bilayer are quite similar. In zone $\mathrm{a}$, it is evident that all receptors' penetration of the bilayer is energetically driven, being favoured by $5.6 \mathrm{kcal} \mathrm{mol}^{-1}$ for $\mathbf{A 1}$, by $10.4 \mathrm{kcal} \mathrm{mol}^{-1}$ for $\mathbf{A} 2$ and by $12.9 \mathrm{kcal} \mathrm{mol}^{-1}$ for $\mathbf{A 3}$. These results are in line with the MD simulation carried out in scenario $\mathrm{W}$, in which the permeation of the water/lipid interface is accompanied by hydrogen bonding interactions to the phospholipid head groups and water molecules. Free A1, A2 and A3 face comparable energy barriers of 9.9, $12.6 \mathrm{kcal}$, $10.8 \mathrm{kcal} \mathrm{mol}^{-1}$, in this order, to surmount the bilayer core. After the energetic barrier, the energy drop to the second basin is of $8.3 \mathrm{kcal} \mathrm{mol}^{-1}$ for $\mathbf{A 1}$, while $\mathbf{A} \mathbf{2}$ and $\mathbf{A} \mathbf{3}$ are favoured by 7.1 and $5.8 \mathrm{kcal} \mathrm{mol}^{-1}$, respectively, to stay in the basin of zone c. Despite the different energetic profiles in zones a to c, receptors A1 and A2 show low energetic barriers to exit the bilayer, 3.6 and $6.5 \mathrm{kcal} \mathrm{mol}^{-1}$ respectively, as also observed for their anion associations. On the other hand, free $\mathbf{A} 3$ has to overcome a higher energy barrier of $c a .8 .7 \mathrm{kcal} \mathrm{mol}^{-1}$ to leave the bilayer. These profiles show that the differences between free $\mathbf{A} \mathbf{1}$ and $\mathbf{A 2}$ to span the bilayer are quite small, while $\mathbf{A} 3$, the most lipophilic molecule, faces several energetic barriers to go from one side of the bilayer to the other.

In summary, these energetic outcomes suggest that squaramides A1-A3 should operate the anion transport event without leaving the phospholipid bilayer, shuttling between both water/ lipid interfaces. In this context, the anion transport by $\mathbf{A 2}$ is thermodynamically favoured when compared with A1 and $\mathbf{A 3}$.

\section{Conclusions}

Squaramide series $\mathbf{C}$ and $\mathbf{D}$, with four and six convergent binding sites respectively, have higher $E^{2}$ and $V_{\mathrm{S}, \max }$ values, and therefore, higher binding affinities for chloride. Overall, the MD simulations showed that these series' molecules are able to recognise and release chloride ions in the water phase and to permeate the water/lipid interface as anion complexes. However, when the chloride complexes of $\mathbf{C}$ and $\mathbf{D}$ are initially positioned in the bilayer core they promptly diffuse towards the membrane interface and are maintained throughout the simulation length. Given that the chloride uptake and release events are condiciones sine quibus non for a small drug-like molecule to operate as an anion carrier, these structural insights are entirely consistent with the absence of experimental transport activity for squaramide derivatives $\mathbf{D}$. The encapsulated chloride is sheltered from the water molecules by the tripodal scaffold architecture of these receptors, as shown by the negligible number of water molecules surrounding the encapsulated anion (see Table 3). The C-series molecules also tightly held chloride, but its hydration is higher than in the $\mathbf{D}$-series, hinting that the release of the anion is more likely, although it has not been observed in the reported MD simulations, but is suggested by the experimental findings.

The A-series molecules, with more moderate $E^{2}$ and $V_{\mathrm{S}, \max }$ values, when located below the phospholipid interface, adopt well-defined spatial dispositions with the $\mathrm{N}-\mathrm{H}$ binding units pointing to the water phase. This orientation enables sporadic exchange of the hydrogen bonded phosphate head groups or water molecules with chloride ions taken from the water phase. In contrast, the B-series molecules, with overall lower $E^{2}$ and $V_{\mathrm{S}, \max }$ values, are also able to bind chloride in water, but, after penetration, due to their asymmetric nature, are unable to preserve a well-defined orientation consistent with occurrence 
of further chloride uptake events. These insights suggest that the A-series molecules are better anion carriers than $\mathbf{B}$, corroborating the experimental transport data.

Our PMF calculations have unequivocally indicated that the chloride transport across the phospholipid bilayer is energetically favoured by the A-series' molecules when compared with its unassisted translocation. The energy profiles of the free A1-A3 on positive $z$-dimension values follow their lipophilicities. For the chloride complexes of these three linear transporters, there is no significant energetic differences for their diffusions until the membrane core.

The experimental anion transport studies in liposomes indicate that the A-series mono-squaramides undoubtedly assist the chloride efflux, mainly through an $\mathrm{Cl}^{-} / \mathrm{NO}_{3}{ }^{-}$antiport mechanism. Although this feature was not theoretically investigated, our MD simulations shows that these carriers are able to easily shuttle within the hydrophobic medium of the phospholipid bilayer as free transporters or as chloride complexes. Furthermore, the chloride uptake and release events can occur in the water phase or, alternatively and more likely, with the squaramides nested at the water/lipid interface level, without surmounting the energy barrier associated with the transporter's membrane exit.

\section{Author contributions}

P. A. G. and V. F. devised the project. I. M. and P. M. R. C. carried out the MD simulations and DFT calculations. I. M. and M. Q. M. analysed the simulations data. N. B., E. N. W. H., H. J. C., and C. J. E. H. synthesised and characterised the compounds, performed the ion-binding studies, and the iontransport studies in liposomes. I. L. K. collected the singlecrystal X-ray data and determined the structures. A. M. R. and R. P. T. performed the biological studies. I. M., N. B. wrote the manuscript together with P. A. G. and V. F.

\section{Conflicts of interest}

There are no conflicts to declare.

\section{Acknowledgements}

The theoretical studies were supported by projects P2020PTDC/QEQ-SUP/4283/2014 and CICECO - Aveiro Institute of Materials (UID/CTM/50011/2013), financed by National Funds through the FCT/MEC and co-financed by QREN-FEDER through COMPETE under the PT2020 Partnership Agreement. I. M. acknowledges FCT for PhD scholarship SFRH/BD/87520/2012. P. A. G. acknowledges the EPSRC for postdoctoral fellowships (EP/J009687/1 to N. B. and E. N. W. H.) and the Royal Society and the Wolfson Foundation for a Research Merit Award. P. A. G. also thanks for the University of Sydney for postdoctoral funding (E. N. W. H.) and the ARC for funding (DP170100118, DP180100612 and LE180100050). The in vitro studies were supported by grants from the Spanish government and the EU (FIS PI13/00089) and La Marato de TV3 Foundation (20132730).

\section{Notes and references}

1 G. G. Celesia, Clin. Neurophysiol., 2001, 112, 2-18.

2 J. LaRusch, J. Jung, I. J. General, M. D. Lewis, H. W. Park, R. E. Brand, A. Gelrud, M. A. Anderson, P. A. Banks, D. Conwell, C. Lawrence, J. Romagnuolo, J. Baillie, S. Alkaade, G. Cote, T. B. Gardner, S. T. Amann, A. Slivka, B. Sandhu, A. Aloe, M. L. Kienholz, D. Yadav, M. M. Barmada, I. Bahar, M. G. Lee, D. C. Whitcomb and North American Pancreatitis Study Group, PLoS Genet., 2014, 10, e1004376.

3 R. Planells-Cases and T. J. Jentsch, Biochim. Biophys. Acta, 2009, 1792, 173-189.

4 P. A. Gale, Coord. Chem. Rev., 2000, 199, 181-233.

5 P. D. Beer and P. A. Gale, Angew. Chem., Int. Ed., 2001, 40, 486-516.

6 P. A. Gale, Coord. Chem. Rev., 2001, 213, 79-128.

7 P. A. Gale, Coord. Chem. Rev., 2003, 240, 191-221.

8 P. A. Gale and R. Quesada, Coord. Chem. Rev., 2006, 250, 3219-3244.

9 A. P. Davis, D. N. Sheppard and B. D. Smith, Chem. Soc. Rev., 2007, 36, 348-357.

10 P. A. Gale, S. E. Garcia-Garrido and J. Garric, Chem. Soc. Rev., 2008, 37, 151-190.

11 C. Caltagirone and P. A. Gale, Chem. Soc. Rev., 2009, 38, 520-563.

12 P. A. Gale, Chem. Soc. Rev., 2010, 39, 3746-3771.

13 J. T. Davis, O. Okunola and R. Quesada, Chem. Soc. Rev., 2010, 39, 3843-3862.

14 S. Matile, A. Vargas Jentzsch, J. Montenegro and A. Fin, Chem. Soc. Rev., 2011, 40, 2453-2474.

15 M. Wenzel, J. R. Hiscock and P. A. Gale, Chem. Soc. Rev., 2012, 41, 480-520.

16 N. Sakai and S. Matile, Langmuir, 2013, 29, 9031-9040.

17 P. A. Gale, N. Busschaert, C. J. Haynes, L. E. Karagiannidis and I. L. Kirby, Chem. Soc. Rev., 2014, 43, 205-241.

18 P. A. Gale, E. N. W. Howe and X. Wu, Chem, 2016, 1, 351-422.

19 P. A. Gale, J. T. Davis and R. Quesada, Chem. Soc. Rev., 2017, 46, 2497-2519.

20 P. A. Gale, E. N. W. Howe, X. Wu and M. J. Spooner, Coord. Chem. Rev., 2018, DOI: 10.1016/j.ccr.2018.02.005.

21 A. J. Ayling, M. N. Perez-Payan and A. P. Davis, J. Am. Chem. Soc., 2001, 123, 12716-12717.

22 L. W. Judd and A. P. Davis, Chem. Commun., 2010, 46, 2227-2229.

23 N. Busschaert, P. A. Gale, C. J. Haynes, M. E. Light, S. J. Moore, C. C. Tong, J. T. Davis and W. A. Harrell, Jr., Chem. Commun., 2010, 46, 6252-6254.

24 N. Busschaert, M. Wenzel, M. E. Light, P. Iglesias-Hernandez, R. Perez-Tomas and P. A. Gale, J. Am. Chem. Soc., 2011, 133, 14136-14148.

25 M. J. Spooner and P. A. Gale, Supramol. Chem., 2018, 30, 514-519.

26 L. Jowett, E. Howe, X. Wu, N. Busschaert and P. A. Gale, Chem. - Eur. J., 2018, DOI: 10.1002/chem.201801463. 
27 B. Diaz de Grenu, P. Iglesias Hernandez, M. Espona, D. Quinonero, M. E. Light, T. Torroba, R. Perez-Tomas and R. Quesada, Chem. - Eur. J., 2011, 17, 14074-14083.

28 E. Hernando, V. Soto-Cerrato, S. Cortes-Arroyo, R. PerezTomas and R. Quesada, Org. Biomol. Chem., 2014, 12, 1771-1778.

29 P. Manuel-Manresa, L. Korrodi-Gregorio, E. Hernando, A. Villanueva, D. Martinez-Garcia, A. M. Rodilla, R. Ramos, M. Fardilha, J. Moya, R. Quesada, V. SotoCerrato and R. Perez-Tomas, Mol. Cancer Ther., 2017, 16, 1224-1235.

30 S. J. Moore, C. J. E. Haynes, J. Gonzalez, J. L. Sutton, S. J. Brooks, M. E. Light, J. Herniman, G. J. Langley, V. Soto-Cerrato, R. Perez-Tomas, I. Marques, P. J. Costa, V. Félix and P. A. Gale, Chem. Sci., 2013, 4, 103-117.

31 L. E. Karagiannidis, C. J. Haynes, K. J. Holder, I. L. Kirby, S. J. Moore, N. J. Wells and P. A. Gale, Chem. Commun., 2014, 50, 12050-12053.

32 C. M. Dias, H. Li, H. Valkenier, L. E. Karagiannidis, P. A. Gale, D. N. Sheppard and A. P. Davis, Org. Biomol. Chem., 2018, 16, 1083-1087.

33 C. C. Tong, R. Quesada, J. L. Sessler and P. A. Gale, Chem. Commun., 2008, 6321-6323.

34 M. G. Fisher, P. A. Gale, J. R. Hiscock, M. B. Hursthouse, M. E. Light, F. P. Schmidtchen and C. C. Tong, Chem. Commun., 2009, 3017-3019.

35 P. A. Gale, C. C. Tong, C. J. Haynes, O. Adeosun, D. E. Gross, E. Karnas, E. M. Sedenberg, R. Quesada and J. L. Sessler, J. Am. Chem. Soc., 2010, 132, 3240-3241.

36 M. Yano, C. C. Tong, M. E. Light, F. P. Schmidtchen and P. A. Gale, Org. Biomol. Chem., 2010, 8, 4356-4363.

37 V. Gorteau, G. Bollot, J. Mareda, A. Perez-Velasco and S. Matile, J. Am. Chem. Soc., 2006, 128, 14788-14789.

38 V. Gorteau, G. Bollot, J. Mareda and S. Matile, Org. Biomol. Chem., 2007, 5, 3000-3012.

39 J. Mareda and S. Matile, Chem. - Eur. J., 2009, 15, 28-37.

40 A. V. Jentzsch, D. Emery, J. Mareda, S. K. Nayak, P. Metrangolo, G. Resnati, N. Sakai and S. Matile, Nat. Commun., 2012, 3, 905.

41 A. Vargas Jentzsch, A. Hennig, J. Mareda and S. Matile, Acc. Chem. Res., 2013, 46, 2791-2800.

42 A. Vargas Jentzsch and S. Matile, J. Am. Chem. Soc., 2013, 135, 5302-5303.

43 A. V. Jentzsch and S. Matile, Top. Curr. Chem., 2015, 358, 205-239.

44 S. Benz, M. Macchione, Q. Verolet, J. Mareda, N. Sakai and S. Matile, J. Am. Chem. Soc., 2016, 138, 9093-9096.

45 S. Tomas, M. C. Rotger, J. F. Gonzalez, P. M. Deya, P. Ballester and A. Costa, Tetrahedron Lett., 1995, 36, 2523-2526.

46 J. O. Morley, THEOCHEM, 1995, 357, 49-57.

47 R. Prohens, S. Tomas, J. Morey, P. M. Deya, P. Ballester and A. Costa, Tetrahedron Lett., 1998, 39, 1063-1066.

48 D. Quinonero, A. Frontera, G. A. Suner, J. Morey, A. Costa, P. Ballester and P. M. Deya, Chem. Phys. Lett., 2000, 326, 247-254.
49 D. Quinonero, A. Frontera, P. Ballester and P. M. Deya, Tetrahedron Lett., 2000, 41, 2001-2005.

50 R. Prohens, M. C. Rotger, M. N. Pina, P. M. Deya, J. Morey, P. Ballester and A. Costa, Tetrahedron Lett., 2001, 42, 4933-4936.

51 D. Quinonero, R. Prohens, C. Garau, A. Frontera, P. Ballester, A. Costa and P. M. Deya, Chem. Phys. Lett., 2002, 351, 115-120.

52 M. Neus Piña, M. Carmen Rotger, A. Costa, P. Ballester and P. M. Deyà, Tetrahedron Lett., 2004, 45, 3749-3752.

53 V. Ramalingam, M. E. Domaradzki, S. Jang and R. S. Muthyala, Org. Lett., 2008, 10, 3315-3318.

54 A. Rostami, A. Colin, X. Y. Li, M. G. Chudzinski, A. J. Lough and M. S. Taylor, J. Org. Chem., 2010, 75, 3983-3992.

55 V. Amendola, G. Bergamaschi, M. Boiocchi, L. Fabbrizzi and M. Milani, Chem. - Eur. J., 2010, 16, 4368-4380.

56 A. Rostami, C. J. Wei, G. Guerin and M. S. Taylor, Angew. Chem., Int. Ed., 2011, 50, 2059-2062.

57 B. W. Gung and S. C. Schlitzer, Tetrahedron Lett., 2015, 56, 5043-5047.

58 J. A. Butera, M. M. Antane, S. A. Antane, T. M. Argentieri, C. Freeden, R. F. Graceffa, B. H. Hirth, D. Jenkins, J. R. Lennox, E. Matelan, N. W. Norton, D. Quagliato, J. H. Sheldon, W. Spinelli, D. Warga, A. Wojdan and M. Woods, J. Med. Chem., 2000, 43, 1187-1202.

59 J. A. Butera, D. J. Jenkins, J. R. Lennox, J. H. Sheldon, N. W. Norton, D. Warga and T. M. Argentieri, Bioorg. Med. Chem. Lett., 2005, 15, 2495-2501.

60 R. I. Storer, C. Aciro and L. H. Jones, Chem. Soc. Rev., 2011, 40, 2330-2346.

61 P. M. Gloria, J. Gut, L. M. Goncalves, P. J. Rosenthal, R. Moreira and M. M. Santos, Bioorg. Med. Chem., 2011, 19, 7635-7642.

62 T. S. Elliott, A. Slowey, Y. L. Ye and S. J. Conway, MedChemComm, 2012, 3, 735-751.

63 S. P. Kumar, P. M. C. Glória, L. M. Gonçalves, J. Gut, P. J. Rosenthal, R. Moreira and M. M. M. Santos, MedChemComm, 2012, 3, 489-493.

64 N. Busschaert, I. L. Kirby, S. Young, S. J. Coles, P. N. Horton, M. E. Light and P. A. Gale, Angew. Chem., Int. Ed., 2012, 51, 4426-4430.

65 X. Wu, N. Busschaert, N. J. Wells, Y. B. Jiang and P. A. Gale, J. Am. Chem. Soc., 2015, 137, 1476-1484.

66 S. J. Edwards, H. Valkenier, N. Busschaert, P. A. Gale and A. P. Davis, Angew. Chem., Int. Ed., 2015, 54, 4592-4596.

67 N. Busschaert, R. B. Elmes, D. D. Czech, X. Wu, I. L. Kirby, E. M. Peck, K. D. Hendzel, S. K. Shaw, B. Chan, B. D. Smith, K. A. Jolliffe and P. A. Gale, Chem. Sci., 2014, 5, 3617-3626.

68 M. Chavent, A. L. Duncan and M. S. Sansom, Curr. Opin. Struct. Biol., 2016, 40, 8-16.

69 S. M. Loverde, J. Phys. Chem. Lett., 2014, 5, 1659-1665.

$70 \mathrm{~W}$. Khuntawee, P. Wolschann, T. Rungrotmongkol, J. Wong-Ekkabut and S. Hannongbua, J. Chem. Inf. Model., 2015, 55, 1894-1902.

71 C. J. E. Haynes, S. J. Moore, J. R. Hiscock, I. Marques, P. J. Costa, V. Félix and P. A. Gale, Chem. Sci., 2012, 3, 1436-1444. 
72 P. J. Costa, I. Marques and V. Félix, Biochim. Biophys. Acta, 2014, 1838, 890-901.

73 I. Marques, A. R. Colaco, P. J. Costa, N. Busschaert, P. A. Gale and V. Félix, Soft Matter, 2014, 10, 3608-3621.

74 S. J. Edwards, I. Marques, C. M. Dias, R. A. Tromans, N. R. Lees, V. Félix, H. Valkenier and A. P. Davis, Chem. - Eur. J., 2016, 22, 2004-2011.

75 N. Busschaert, S. H. Park, K. H. Baek, Y. P. Choi, J. Park, E. N. W. Howe, J. R. Hiscock, L. E. Karagiannidis, I. Marques, V. Félix, W. Namkung, J. L. Sessler, P. A. Gale and I. Shin, Nat. Chem., 2017, 9, 667-675.

76 C. Jin, M. Zhang, L. Wu, Y. Guan, Y. Pan, J. Jiang, C. Lin and L. Wang, Chem. Commun., 2013, 49, 2025-2027.

77 N. Busschaert and P. A. Gale, Angew. Chem., Int. Ed., 2013, 52, 1374-1382.

78 C. Jin, M. Zhang, C. Deng, Y. F. Guan, J. Gong, D. R. Zhu, Y. Pan, J. L. Jiang and L. Y. Wang, Tetrahedron Lett., 2013, 54, 796-801.

79 Y. Liu, Y. Qin and D. Jiang, Analyst, 2015, 140, 5317-5323.

80 M. J. Frisch, G. W. Trucks, H. B. Schlegel, G. E. Scuseria, M. A. Robb, J. R. Cheeseman, G. Scalmani, V. Barone, B. Mennucci, G. A. Petersson, H. Nakatsuji, M. Caricato, X. Li, H. P. Hratchian, A. F. Izmaylov, J. Bloino, G. Zheng, J. L. Sonnenberg, M. Hada, M. Ehara, K. Toyota, R. Fukuda, J. Hasegawa, M. Ishida, T. Nakajima, Y. Honda, O. Kitao, H. Nakai, T. Vreven, J. A. Montgomery, Jr, J. E. Peralta, F. Ogliaro, M. Bearpark, J. J. Heyd, E. Brothers, K. N. Kudin, V. N. Staroverov, R. Kobayashi, J. Normand, K. Raghavachari, A. Rendell, J. C. Burant, S. S. Iyengar, J. Tomasi, M. Cossi, N. Rega, J. M. Millam, M. Klene, J. E. Knox, J. B. Cross, V. Bakken, C. Adamo, J. Jaramillo, R. Gomperts, R. E. Stratmann, O. Yazyev, A. J. Austin, R. Cammi, C. Pomelli, J. W. Ochterski, R. L. Martin, K. Morokuma, V. G. Zakrzewski, G. A. Voth, P. Salvador, J. J. Dannenberg, S. Dapprich, A. D. Daniels, Ö. Farkas, J. B. Foresman, J. V. Ortiz, J. Cioslowski and D. J. Fox, Gaussian 09, Revision A.02, Gaussian, Inc., Wallingford, CT, 2009.

81 D. Case, J. T. Berryman, D. S. S. R. M. Betz, T. E. Cheatham, T. A. Darden, R. E. Duke, T. J. Giese, H. Gohlke, A. W. Goetz, N. Homeyer, S. Izadi, P. Janowski, J. Kaus, A. Kovalenko, T. S. Lee, S. LeGrand, P. Li, R. Luo, B. Madej, K. M. Merz, G. Monard, P. Needham, H. Nguyen, H. T. Nguyen, I. Omelyan, A. Onufriev, D. R. Roe, A. Roitberg, R. Salomon-Ferrer, C. L. Simmerling, W. Smith, J. Swails, R. C. Walker, J. Wang, R. M. Wolf, X. Wu, D. M. York and P. A. Kollman, AMBER 14, University of California, San Francisco, 2014.

82 J. C. Phillips, R. Braun, W. Wang, J. Gumbart, E. Tajkhorshid, E. Villa, C. Chipot, R. D. Skeel, L. Kale and K. Schulten, J. Comput. Chem., 2005, 26, 1781-1802.

83 D. A. Case, R. M. Betz, D. S. Cerutti, T. E. Cheatham, III, T. A. Darden, R. E. Duke, T. J. Giese, H. Gohlke,
A. W. Goetz, N. Homeyer, S. Izadi, P. Janowski, J. Kaus, A. Kovalenko, T. S. Lee, S. LeGrand, P. Li, C. Lin, T. Luchko, R. Luo, B. Madej, D. Mermelstein, K. M. Merz, G. Monard, H. Nguyen, H. T. Nguyen, I. Omelyan, A. Onufriev, D. R. Roe, A. Roitberg, C. Sagui, C. L. Simmerling, W. M. BotelloSmith, J. Swails, R. C. Walker, J. Wang, R. M. Wolf, X. Wu, L. Xiao and P. A. Kollman, AMBER 2016, University of California, San Francisco, 2016.

84 A. W. Gotz, M. J. Williamson, D. Xu, D. Poole, S. Le Grand and R. C. Walker, J. Chem. Theory Comput., 2012, 8, 1542-1555.

85 R. Salomon-Ferrer, A. W. Gotz, D. Poole, S. Le Grand and R. C. Walker, J. Chem. Theory Comput., 2013, 9, 3878-3888.

86 S. Le Grand, A. W. Götz and R. C. Walker, Comput. Phys. Commun., 2013, 184, 374-380.

87 C. J. Dickson, B. D. Madej, A. A. Skjevik, R. M. Betz, K. Teigen, I. R. Gould and R. C. Walker, J. Chem. Theory Comput., 2014, 10, 865-879.

88 J. Wang, R. M. Wolf, J. W. Caldwell, P. A. Kollman and D. A. Case, J. Comput. Chem., 2004, 25, 1157-1174.

89 J. Wang, R. M. Wolf, J. W. Caldwell, P. A. Kollman and D. A. Case, J. Comput. Chem., 2005, 26, 114.

90 C. I. Bayly, P. Cieplak, W. D. Cornell and P. A. Kollman, J. Phys. Chem., 1993, 97, 10269-10280.

91 X. J. Cai, Z. Li and W. H. Chen, Bioorg. Med. Chem. Lett., 2017, 27, 1999-2002.

92 X. Wu, L. W. Judd, E. N. W. Howe, A. M. Withecombe, V. Soto-Cerrato, H. Li, N. Busschaert, H. Valkenier, R. Perez-Tomas, D. N. Sheppard, Y. B. Jiang, A. P. Davis and P. A. Gale, Chem, 2016, 1, 127-146.

93 P. Politzer and D. G. Truhlar, Chemical Applications of Atomic and Molecular Electrostatic Potentials, Springer US, 1st edn, 1981.

94 A. E. Reed, L. A. Curtiss and F. Weinhold, Chem. Rev., 1988, 88, 899-926.

95 C. E. Silva, H. F. Dos Santos, N. L. Speziali, R. Diniz and L. F. de Oliveira, J. Phys. Chem. A, 2010, 114, 10097-10109.

96 MarvinSketch, 16.5.16.0, ChemAxon Ltd, Budapest, Hungary, 2016.

97 S. Kumar, J. M. Rosenberg, D. Bouzida, R. H. Swendsen and P. A. Kollman, J. Comput. Chem., 1992, 13, 1011-1021.

98 B. Roux, Comput. Phys. Commun., 1995, 91, 275-282.

99 A. Grossfield, WHAM: The Weighted Histogram Analysis Method, 2.0.9.1, Grossfield Lab, University of Rochester, New York, 2017.

100 B. Efron and R. J. Tibshirani, An Introduction to the Bootstrap, Chapman \& Hall and CRC, New York, 1993.

101 H. A. Filipe, M. J. Moreno, T. Rog, I. Vattulainen and L. M. Loura, J. Phys. Chem. B, 2014, 118, 3572-3581.

102 C. T. Lee, J. Comer, C. Herndon, N. Leung, A. Pavlova, R. V. Swift, C. Tung, C. N. Rowley, R. E. Amaro, C. Chipot, Y. Wang and J. C. Gumbart, J. Chem. Inf. Model., 2016, 56, 721-733. 